\title{
Diurnal variations of stratospheric ozone measured by ground-based microwave remote sensing at the Mauna Loa NDACC site: measurement validation and GEOSCCM model comparison
}

\author{
A. Parrish ${ }^{1}$, I. S. Boyd ${ }^{2}$, G. E. Nedoluha ${ }^{3}$, P. K. Bhartia ${ }^{4}$, S. M. Frith ${ }^{5}$, N. A. Kramarova ${ }^{5}$, B. J. Connor ${ }^{6}$, \\ G. E. Bodeker ${ }^{7}$, L. Froidevaux ${ }^{8}$, M. Shiotani ${ }^{9}$, and T. Sakazaki ${ }^{9}$ \\ ${ }^{1}$ Department of Astronomy, University of Massachusetts, Amherst, MA, USA \\ ${ }^{2}$ Contractor to BC Scientific Consulting LLC, USA \\ ${ }^{3}$ Naval Research Laboratory, Washington, DC, USA \\ ${ }^{4}$ NASA-Goddard Space Flight Center, Greenbelt, MD, USA \\ ${ }^{5}$ SSAI, Lanham, MD, USA \\ ${ }^{6}$ BC Scientific Consulting LLC, Wellington, New Zealand \\ ${ }^{7}$ Bodeker Scientific, Alexandra, New Zealand \\ ${ }^{8}$ Jet Propulsion Laboratory, Pasadena, CA, USA \\ ${ }^{9}$ Research Institute for Sustainable Humanosphere, Kyoto University, Uji, Japan
}

Correspondence to: A. Parrish (parrish@astro.umass.edu) and I. S. Boyd (iboyd@astro.umass.edu)

Received: 7 October 2013 - Published in Atmos. Chem. Phys. Discuss.: 6 December 2013

Revised: 2 June 2014 - Accepted: 2 June 2014 - Published: 16 July 2014

\begin{abstract}
There is presently renewed interest in diurnal variations of stratospheric and mesospheric ozone for the purpose of supporting homogenization of records of various ozone measurements that are limited by the technique employed to being made at certain times of day. We have made such measurements for 19 years using a passive microwave remote sensing technique at the Mauna Loa Observatory (MLO) in Hawaii, which is a primary station in the Network for Detection of Atmospheric Composition Change (NDACC). We have recently reprocessed these data with hourly time resolution to study diurnal variations. We inspected differences between pairs of the ozone spectra (e.g., day and night) from which the ozone profiles are derived to determine the extent to which they may be contaminated by diurnally varying systematic instrumental or measurement effects. These are small, and we have reduced them further by selecting data that meet certain criteria that we established. We have calculated differences between profiles measured at different times: morning-night, afternoon-night, and morning-afternoon and have intercompared these with like profiles derived from the Aura Microwave Limb Sounder (Aura-MLS), the Upper Atmosphere
\end{abstract}

Research Satellite Microwave Limb Sounder (UARS-MLS), the Superconducting Submillimeter-Wave Limb-Emission Sounder (SMILES), and Solar Backscatter Ultraviolet version 2 (SBUV/2) measurements. Differences between averages of coincident profiles are typically $<1.5 \%$ of typical nighttime values over most of the covered altitude range with some exceptions. We calculated averages of ozone values for each hour from the Mauna Loa microwave data, and normalized these to the average for the first hour after midnight for comparison with corresponding values calculated with the Goddard Earth Observing System Chemistry Climate Model (GEOSCCM). We found that the measurements and model output mostly agree to better than $1.5 \%$ of the midnight value, with one noteworthy exception: The measured morning-night values are significantly $(2-3 \%)$ higher than the modeled ones from 3.2 to $1.8 \mathrm{hPa}(\sim 39-43 \mathrm{~km})$, and there is evidence that the measured values are increasing compared to the modeled values before sunrise in this region. 


\section{Introduction}

Chapman (1930) first described a theory that, although it included only five reactions between various oxygen species and did not consider dynamics, predicted several of the major features of the stratospheric ozone layer. The reactions include the formation of the precursors of ozone by photodissociation of molecular oxygen,

$\mathrm{O}_{2}+h v \rightarrow \mathrm{O}+\mathrm{O}$

ozone,

$\mathrm{O}_{3}+h v \rightarrow \mathrm{O}+\mathrm{O}_{2}$,

and

$\mathrm{O}_{3}+h v \rightarrow \mathrm{O}(1 \mathrm{D})+\mathrm{O}_{2}$.

The latter products re-form ozone via the reaction

$\mathrm{O}_{2}+\mathrm{O}+\mathrm{M} \rightarrow \mathrm{O}_{3}+\mathrm{M}$,

where $\mathrm{M}$ is a third, non-reacting atom or molecule that must be simultaneously involved with the oxygen species to carry away the energy liberated in the reaction. The solar energy absorbed in this cycle is the main source of heating in the stratosphere and contributes strongly to the observed increase in atmospheric temperature with altitude in this region. Branch (2b) of the ozone photodissociation reaction absorbs strongly at wavelengths $<310 \mathrm{~nm}$, and filters out the biologically damaging solar UVB radiation ( 280 to $320 \mathrm{~nm}$ ) that would otherwise reach the Earth's surface. This science was of little interest to international policymakers until the realization that ozone could also be destroyed globally in a catalytic cycle by chlorine initially released in the upper stratosphere by photodissociation of human-made chlorofluorocarbons (Rowland and Molina, 1975). This, and the later discovery of the Antarctic ozone "hole" (Farman et al, 1985), led to much more intensive study of the upper atmosphere through measurements of the relevant oxygen, hydrogen, nitrogen, chlorine and bromine species, laboratory measurements of their reaction rates, and computational modeling of the chemistry and dynamics of the stratosphere using these data. These efforts convinced policymakers to enact the Montreal Protocol (UNEP, 2006). As a result of this international treaty, the level of ozone-depleting substances (ODS) peaked in 1996 and has since been declining (WMO, 2011). This assessment concluded that the ozone decline from 1980 to the mid-1990s ceased around 1996. It also noted that while the trend values seen from 1996 to 2008 were positive and consistent with expected ozone recovery, they were not statistically significant. Further refinement of ozone records will reduce the time required to make the latter detection with a high degree of confidence.

The effort to determine the long-term behavior of stratospheric ozone profiles has relied upon measurements made with a variety of satellite and ground-based instruments employing various physical techniques. No single individual instrument has produced a highly stable, global record of ozone profiles over the entire period of interest. The longest such record to date was produced from 1984 to 2005 by the Stratospheric Aerosol and Gas Experiment (SAGE-II) instrument. Past analyses, e.g., SPARC (1998), relied heavily on the SAGE-II data set. A complete record from, say, the 1980s to the present must therefore be assembled from multiple shorter records. This requires evaluating effects of, e.g., systematic measurement drift due to instrument degradation and calibration offsets between individual instruments or instrument types on the assembled record. In addition to these measurement issues, real diurnal ozone variations must be accounted for when combining records from instruments that make measurements at different times of day. For example, SAGE-II made measurements only at sunrise and sunset. There are also diurnal issues with data from the several Solar Backscatter Ultraviolet (SBUV, SBUV/2) instruments because the orbits of most of their carrier satellites drifted in such a manner that the times of their measurements over a given location changed by several hours over the course of a few years. Thus, an accurate understanding of diurnal ozone variations facilitates the effort of combining these and other measurements into an accurate and homogeneous long-term climate data record for ozone.

The fact that the reactions listed above and many others in the contemporary understanding of upper atmospheric chemistry involve photodissociation implies that diurnal variations will occur as long as the reaction time constants are $\ll 24 \mathrm{~h}$. To take a simple example, because reaction (3) requires the simultaneous presence of three species to occur, its rate is proportional to the square of the density. Thus, in the mesosphere, where the density is very low, reaction (3) occurs much less rapidly than (2), and nearly all of the odd oxygen $\left(\mathrm{O}+\mathrm{O}_{3}\right)$ is in atomic form during the day but quickly forms ozone through (3) at sunset. As figures in this and earlier papers, e.g., Connor et al. (1994) show, daytime ozone mixing ratios in the mesosphere are $\sim 70 \%$ less than nighttime reference values at $0.1 \mathrm{hPa}$. As altitude decreases and pressure increases the diurnal variations quickly become smaller. Between 1 and $5 \mathrm{hPa}$ they are small enough that they attracted little attention until Huang et al. (1997) analyzed UARSMLS data and claimed detection of an afternoon ozone enhancement (when compared to evening and morning values) of several percent at $3 \mathrm{hPa}$. There were concerns about this result because the same analysis showed unexpectedly large diurnal variations at lower levels, e.g., $10 \mathrm{hPa}$. Haefele et al. (2008) also reported the afternoon enhancement based on their ground-based microwave measurements and attributed it to continuing ozone formation during the day through reaction (3) and the relatively high density and consequent low $\mathrm{O} / \mathrm{O}_{3}$ ratio. Other midlatitude ground-based microwave results reported by Connor et al. (1994), Ogawa et al. (1996), and Studer et al. (2013) are qualitatively consistent with the Haefele results, in that all show afternoon enhancement in the range 3-6 hPa when averages are taken over several months. 
So, numerous ground- and satellite-based measurements support the existence of the afternoon enhancement. However, it is not clear that the amount of enhancement has been established at the $1 \%$ level. There are statistically significant differences between some of the plots of relative ozone mixing ratio as a function of local time in the papers referenced above. Possible causes for these differences include differences in resolution, season, altitude or latitude, interannual variations, and systematic measurement errors.

Diurnal measurements are made most conveniently with a space- or ground-based spectroscopic instrument that measures an ozone emission line at microwave or infrared wavelengths. These lines are excited by intermolecular collisions, so no external source of illumination is required for observations and they can be made either during the day or at night. However, infrared measurements may be subject to errors if the transition involved is not in local thermodynamic equilibrium, as noted by Connor et al. (1994). This is not an issue for transitions in the microwave region because there the energy levels are more closely spaced. While ground-based emission measurements can be made over the full $24 \mathrm{~h}$, weather permitting, they are limited to the few locations where such instruments are sited. Satellite-based measurements typically cover a wide range of latitudes, but have limitations arising from the nature of their orbits. For example, the Aura satellite carrying the second JPL Microwave Limb Sounder (hereafter Aura-MLS) is in a sun-synchronous orbit, so it passes over a given location only twice per day. The orbit of the UARS satellite carrying the first MLS (hereafter UARS-MLS) precessed such that it cycled through $24 \mathrm{~h}$ over a given location once every $\sim 36$ days, which allowed complete diurnal sampling. Likewise, the orbit of the International Space Station carrying the Superconducting Submillimeter-Wave Limb-Emission Sounder (hereafter SMILES) cycled through $24 \mathrm{~h}$ every 60 days, enabling the diurnal observations reported by Sakazaki et al. (2013). In such cases, seasonal ozone variations must be accounted for when comparing a measurement at one time of day with that from another, as the latter may have been taken several tens of days later or earlier, depending on the rate of precession of the satellite orbit. There have been several approaches to this problem. For example, Huang et al. (1997, 2010) separated the diurnal and seasonal components in UARS-MLS data by making Fourier series of these two components out of time series of the data. Sakazaki et al. (2013) extracted the diurnal variations from the SMILES data by subtracting a 30 day running mean of the time series from the original data. These two approaches gave quite different results, particularly in the lower stratosphere. The amplitude of the equatorial diurnal variations derived from UARS-MLS data shown in Fig. 6 in Huang et al. (2010) at $32 \mathrm{hPa}(\sim 24 \mathrm{~km})$ are 5 to $10 \%$ of the midnight value during spring and summer in the tropics, while they are $\leq 0.05$ ppm $(\sim 2 \%)$ in Fig. 5 in Sakazaki et al. (2013) and in this paper. These differences could be due either to the analysis technique or to real differences between the two data sets. The first possibility can be avoided by comparing only measurements made at specific times of day, as we do in this paper, but these are limited to the available satellite overpass times.

Models could also be used to determine diurnal adjustments when homogenizing multiple data sets, provided they adequately represent the complex chemical and dynamical phenomena in the atmosphere. However, differences up to $4 \%$ in the afternoon enhancement have been reported in comparisons of several models, for example in Fig. 6 displayed in Haefele, et al. (2008) for summer at $3 \mathrm{hPa}$. Recent comparisons of SMILES data with two chemical climate models (Sakazaki et al., 2013) show good agreement, suggesting that current models may be becoming sufficiently sophisticated to use for data set homogenization. To contribute to this research, we compare carefully controlled and calibrated measurements made with the ground-based NDACC microwave ozone profiling radiometer (MWR) at Mauna Loa, Hawaii $\left(19.5^{\circ} \mathrm{N}, 204.5^{\circ} \mathrm{E}\right)$ with available output from the NASA-GEOSCCM model in this paper. These are the first ground-based diurnal ozone measurements at tropical latitudes.

The remainder of this paper is organized as follows: Sect. 2 discusses the MWR measurements, the work we did to understand and minimize small instrumental effects on the measurements and the selection of data that we then made. Section 3 compares the MWR measurements to those made with the satellite-borne Aura-MLS, UARS-MLS, SMILES, and several SBUV/2 instruments to establish the degree of agreement between these resources and confirm the quality of the MWR data. Technical references for these instruments are also given in this section. Section 4 discusses the modelmeasurement comparison. Section 5 summarizes the work.

\section{Ground-based microwave measurements at Mauna Loa}

The Mauna Loa MWR has been in operation since 1995. The instrument consists of a heterodyne receiver coupled to a 120 channel filter spectrometer. It measures the emission spectrum of a line produced by a thermally excited, purely rotational ozone transition at $110.836 \mathrm{GHz}(2.7 \mathrm{~mm}$ wavelength). The spectral intensities and measurements of the tropospheric thermal emission are calibrated with black body sources at ambient and liquid nitrogen temperatures. The tropospheric absorption of the stratospheric ozone signal is calculated from hourly measurements of the tropospheric thermal radiation. The experimental technique was described in Parrish et al. (1992), and technical details on the instrument used for this work are given in Parrish (1994).

The fact that the Mauna Loa NDACC site is at an altitude of $3400 \mathrm{~m}$ contributes to the quality of the measurements. The zenith tropospheric opacity there is typically $\sim 0.08$ nepers, corresponding to tropospheric transmission of 
$\sim 92 \%$. For comparison, the opacity observed with the essentially identical MWR at the low altitude ( $370 \mathrm{~m})$ NDACC site at Lauder, New Zealand is typically around 0.25 nepers. A fractional error in the absorption measurement will therefore have about a factor of 3 smaller effect on the calibration at the Mauna Loa site.

One technical point that is pertinent to the discussion that follows is that the instrument was designed so that the elevation angle of the primary signal beam (the line of sight through the atmosphere) is automatically adjusted to compensate for weather-induced variations in the tropospheric opacity. The compensation technique and the need for it are discussed in Parrish et al. (1988). The elevation angle increases approximately linearly with the tropospheric opacity. The peak of the distribution of the number of observations as a function of the elevation angle at which they were made is at $12.5^{\circ}$. The instrument typically operates at or within a few degrees above this value when the weather is clear or clouds are thin. As the weather degrades, the elevation angle increases and the distribution decreases smoothly from its peak. The number of measurements made at elevation angles above $\sim 24^{\circ}$ is negligible. When the weather is exceptionally good, the distribution drops off quickly from its peak to zero at $\sim 10^{\circ}$.

The ozone mixing ratio profiles are retrieved from the spectra using an adaptation of the optimal estimation method of Rodgers (1976), discussed in Parrish et al. (1992) and Connor et al. (1995). Our error analysis techniques are discussed in the latter paper. The independent variable in the retrieval system is pressure; we give approximate corresponding altitudes in the text and figures in some instances for convenience. We define the vertical resolution of the measurements as the full width to half maximum of the typical averaging kernels. The derivation of the averaging kernels and the resolution are described in Connor et al. (1995). The kernel full width to half maximum is smallest at $6 \mathrm{~km}$ at an altitude of $32 \mathrm{~km}$, lies between 6 and $8 \mathrm{~km}$ between 20 and $42 \mathrm{~km}$, and then increases to $14 \mathrm{~km}$ at $65 \mathrm{~km}$. The kernel maxima fall at their nominal pressure levels throughout the 56 to $0.1 \mathrm{hPa}(\sim 20$ to $65 \mathrm{~km})$ range, so that the true ozone value at a nominal pressure level has the highest weighting in the retrieved value at that level. Their widths are smaller than those described in Connor et al. $(1994,1995)$ due to instrumental and procedural improvements and retrieval parameter readjustments which are applicable to the present version 6 of the MWR data. They are up to nearly a factor of 2 smaller than those reported for some of the ground-based microwave experiments referred to in Sect. 1.

We reprocessed the MLO 1995 to 2013 MWR data with hourly time resolution for use in this work. While this resolution is not adequate for studying the rapid ozone transitions in the mesosphere at sunrise and sunset, it suffices to observe slower diurnal variations at other times of day. The processing procedures for these data are the same as those for the standard MLO MWR product that is submitted to the
NDACC database. The hourly data are not included in the submission, but are available from the corresponding author upon request.

\subsection{A note on units}

Data and plots presented in this paper have been normalized to reference values, and results have been expressed in percent, i.e., Percent $=100.0 \times\left(\mathrm{VMR}_{\mathrm{DATA}}-\right.$ $\left.\mathrm{VMR}_{\mathrm{REF}}\right) / \mathrm{VMR}_{\mathrm{REF}}$, where $\mathrm{VMR}_{\mathrm{DATA}}$ are the data being normalized, in units of volume mixing ratio, and VMR REF are the pressure-corresponding reference data. The original data from all instruments except SMILES were provided in units of volume mixing ratio (VMR) vs. pressure. The SMILES data were converted as described in Sect. 3. Unless otherwise noted, the reference data were taken at night. The times at which the reference data were taken are noted in the text or in the figures. In the following comparisons between two profiles taken under different conditions or with different instruments, quoted values represent the differences between pressure-corresponding data points in the profiles. While these are absolute differences, they are expressed in percent because the profiles being compared are given in units of percent.

\subsection{Study and mitigation of diurnally varying errors in the microwave measurements}

We found that the measurements were being affected by diurnal temperature variations within the small outbuilding (hereafter referred to as "room") housing the instrument. While the temperatures we theoretically need to process the raw data are automatically measured, recorded and utilized in the analysis, there appear to be small secondary temperature effects on the measurements. The largest room temperature changes occurred on cold and windy nights when there was not enough heat available to keep the room temperature at the thermostat setting. The temperature would also occasionally rise above this setting during the warmest sunny days. About three-quarters of all measurements between 2004 and 2012 were made with the room temperature controlled by the thermostat, which is typically set to $20^{\circ} \mathrm{C}$.

We compared day-night difference profiles made up from data taken at temperatures within $\pm 1.2^{\circ} \mathrm{C}$ of the thermostat setting to data taken at all room temperatures, and the results are shown in Fig. 1. This figure shows the percentage differences vs. pressure between our daytime (early afternoon, $12: 36$ to $13: 36$ LST, 23:00 to 24:00 UTC) and nighttime (01:36 to 02:36 LST, $12: 00$ to 13:00 UTC) measurements averaged over the period August 2004 to March 2013. The day- and night- times used were those of the Aura-MLS overpasses so that this figure is comparable to others shown later. The violet line shows the result obtained if we use data processed with the standard quality selection criteria that are applied to MWR data submitted to the NDACC database, 


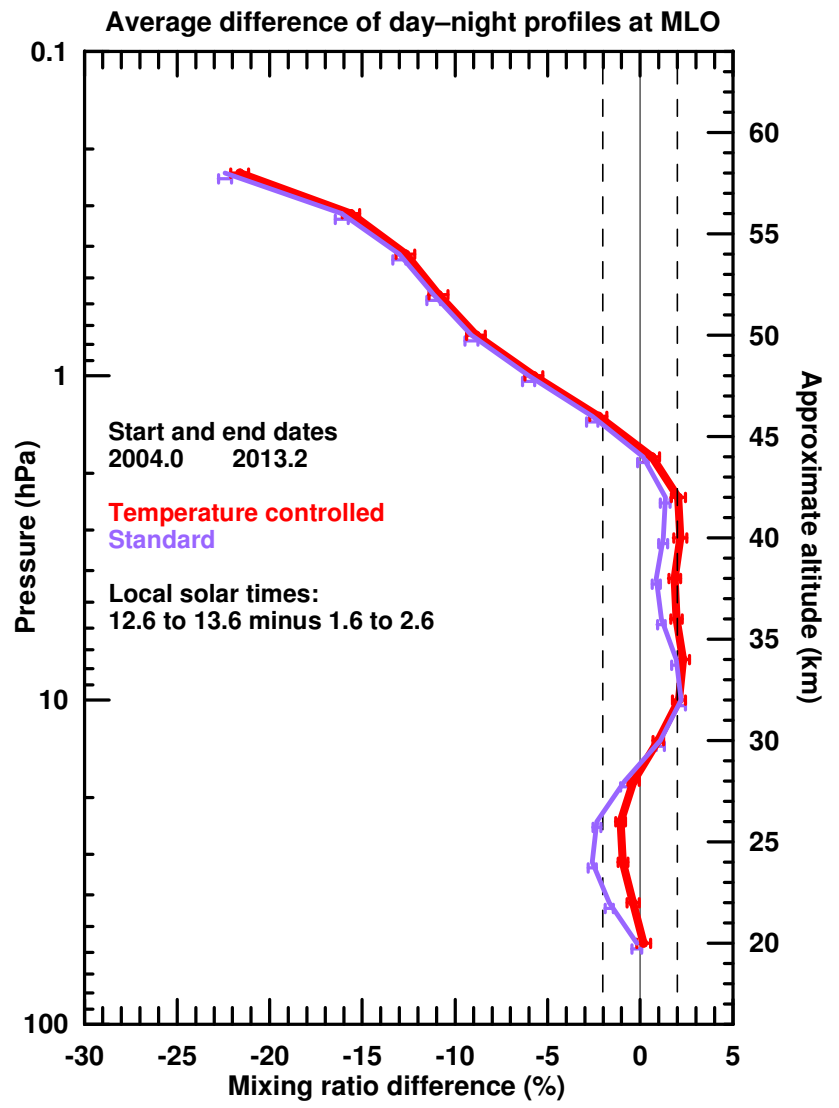

Figure 1. MWR measurements of daytime (12:36 to 13:36 LST) minus nighttime (01:36 to 02:36 LST) ozone differences at Mauna Loa from data recorded within $1.2^{\circ} \mathrm{C}$ of the room thermostat setting (red) and standard data without this restriction (violet), as described in the text. Individual measurements were averaged over the period January 2004 to March 2013 and combined and normalized as described in Sect. 2.1 to make this figure. The error bars are set equal to $2 \times \mathrm{rms} \times n^{-0.5}$, where $n$ is the number of individual measurements in the average for each data point and rms is the root-meansquare of the individual values in that set of measurements. The vertical positions of the error bars have been offset slightly from their nominal pressure values to display the errors more clearly. Vertical dotted lines at $\pm 2 \%$ are provided as a guide to the eye.

hereafter designated "standard" data. The red line shows the result obtained if we select data meeting the temperature criteria described above in addition to the standard criteria. They are designated hereafter as "temperature controlled" data in the text and figure captions. These two profiles have apparent local minima at $\sim 24$ and $\sim 37 \mathrm{~km}$ and a local maximum at $\sim 32 \mathrm{~km}$. The maximum and minima are effects of the retrieval process in combination with residual systematic errors in the spectra. The retrieval tends to alternately overestimate and underestimate (or vice versa) the ozone values as altitude increases, and systematic spectral errors drive up the amplitude of these variations, as discussed below. The amplitude of these variations is reduced by a factor of about 2

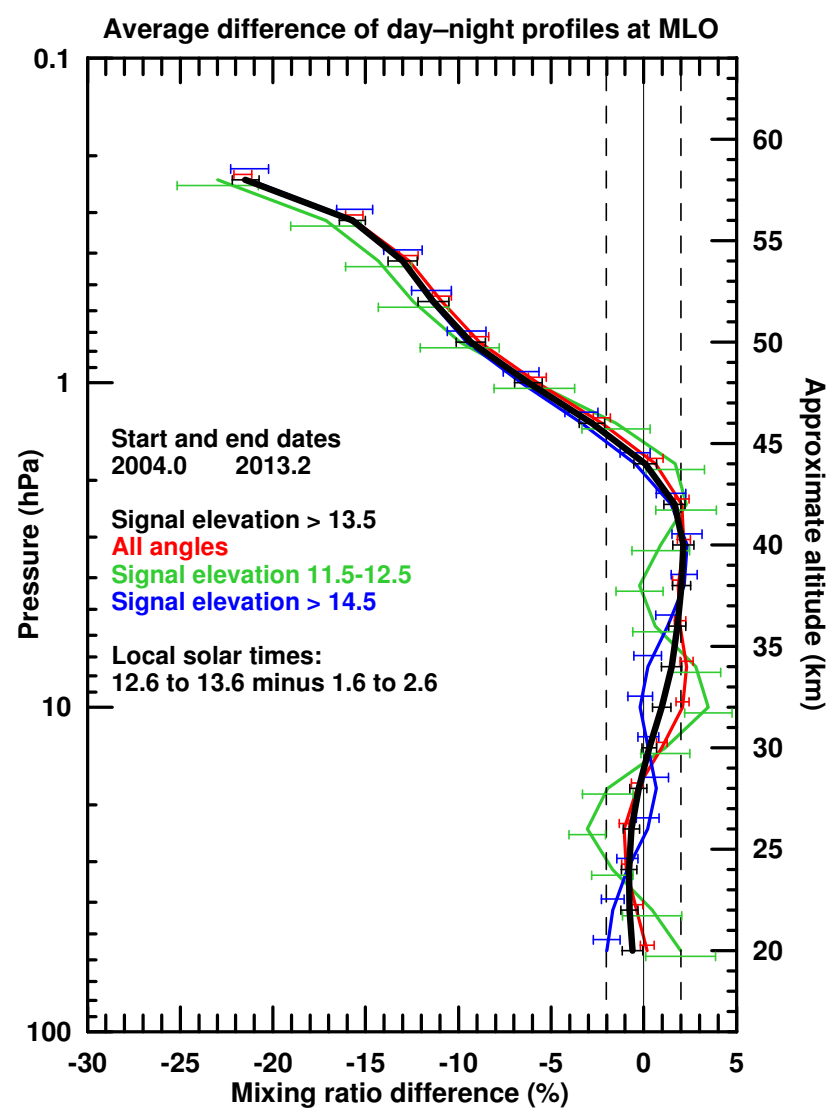

Figure 2. Day-night difference profiles derived from data that were recorded when the room temperature was well controlled and the signal beam elevation angle was within specified limits, as follows: black; selected data, as used for this work, with elevation angle $>13.5^{\circ}$; red, no angle limits, corresponding to the red profile in Fig. 1; green, 11.5 to $12.5^{\circ}$; blue, $>14.5^{\circ}$. Errors and other details are as described in the caption for Fig. 1. See text for discussion of the profiles.

when the data are controlled for temperature. Another feature in Fig. 1 is that the values in the temperature controlled profile are up to $\sim 1 \%$ larger than the corresponding values in the standard profile. This could be an effect of selecting out the tropospheric conditions that produce the windy weather, or a presently unknown, temperature-dependent instrumental calibration error. In either case, we believe that reducing the range of diurnal temperature variations should lead to improved accuracy in the diurnal difference profile measurements, and therefore use only temperature controlled data for the work presented below.

We also found that details in our diurnal difference profiles depended on the range of signal beam elevation angles (discussed in Sect. 2.0) over which they were taken. Figure 2 gives several examples that display maxima and minima similar to those shown in Fig. 1. The red profile corresponds to the red profile in Fig. 1. The others show results obtained if we select measurements that meet the temperature criteria 
and also were made within the indicated ranges of signal beam elevation angles. These lines have very nearly the same pattern as the red line except that the magnitudes of the minima and maxima are increased if the lower $\left(11.5^{\circ}\right.$ to $\left.12.5^{\circ}\right)$ elevation angle range is used (green) and nearly eliminated if only data taken at elevation angles $>13.5^{\circ}$ are used (black). We chose the angles for the former profile to force a worstcase condition and clearly demonstrate the maxima and minima. The blue profile shows the effect of restricting elevation angles to $>14.5^{\circ}$. In this case, the small local maxima reappear where the minima are on the other profiles, and vice versa. We argue below that the data selection leading to the black profile is optimum for this work.

\subsubsection{Systematic error tests using spectral differences}

We inspected day (designated D) minus night (designated $\mathrm{N}$ ) difference spectra to see what effect the beam elevation angle range had on the differential systematic spectral errors. The fact that the true spectrum of an ozone line is symmetric about its center provides a means for detecting artifacts in a measured spectrum. Other features in the difference spectra are systematic artifacts. They will introduce errors in the corresponding retrieved difference profiles unless they are perfectly antisymmetric about the ozone line center, which is unlikely. The intensities of the ozone signals seen in the individual $\mathrm{D}$ and $\mathrm{N}$ spectra depend on the signal beam elevation angle $\theta$ and zenith tropospheric opacity $\tau_{z}$ at the times the observations were made, and these parameters may differ from one observation to another. Their intensity scales are therefore renormalized to account for $\theta$ and $\tau_{z}$ at the times that the $\mathrm{D}$ and $\mathrm{N}$ measurements were made. The spectra were scaled as if the observations were made at the long term average values of $\theta$ and $\tau_{z}\left(14.1^{\circ}\right.$ and 0.09 nepers, respectively). All but the small differences between spectra $\mathrm{D}$ and $\mathrm{N}$ then cancel out when the second is subtracted from the first. We then prepared averages of these D-N spectra over extended periods of time to reduce the noise. Those in Fig. 3 were averaged over the same period and times of day as the corresponding profiles presented in Fig. 2. The differenced ozone line is the central feature in the spectrum. The intensity of this feature cannot be intuitively interpreted because $\theta$ is not constant and the atmosphere is not plane parallel. The large negative feature at the center of the spectrum is due to the reduced values of daytime ozone relative to those at nighttime in the upper stratosphere and mesosphere. It is shown with an expanded frequency scale in the bottom panel of Fig. 3. It is very narrow because the spectral pressure broadening is small, given the low atmospheric pressure in this region. The surrounding symmetric positive features seen in the top panel of the figures are due to enhanced daytime ozone in the region of 1 to $10 \mathrm{hPa}$.

The quasi-sinusoidal feature seen most prominently on the left side of the green spectrum in Fig. 3 is an asymmetric artifact. This curve corresponds to the forced worst-case green
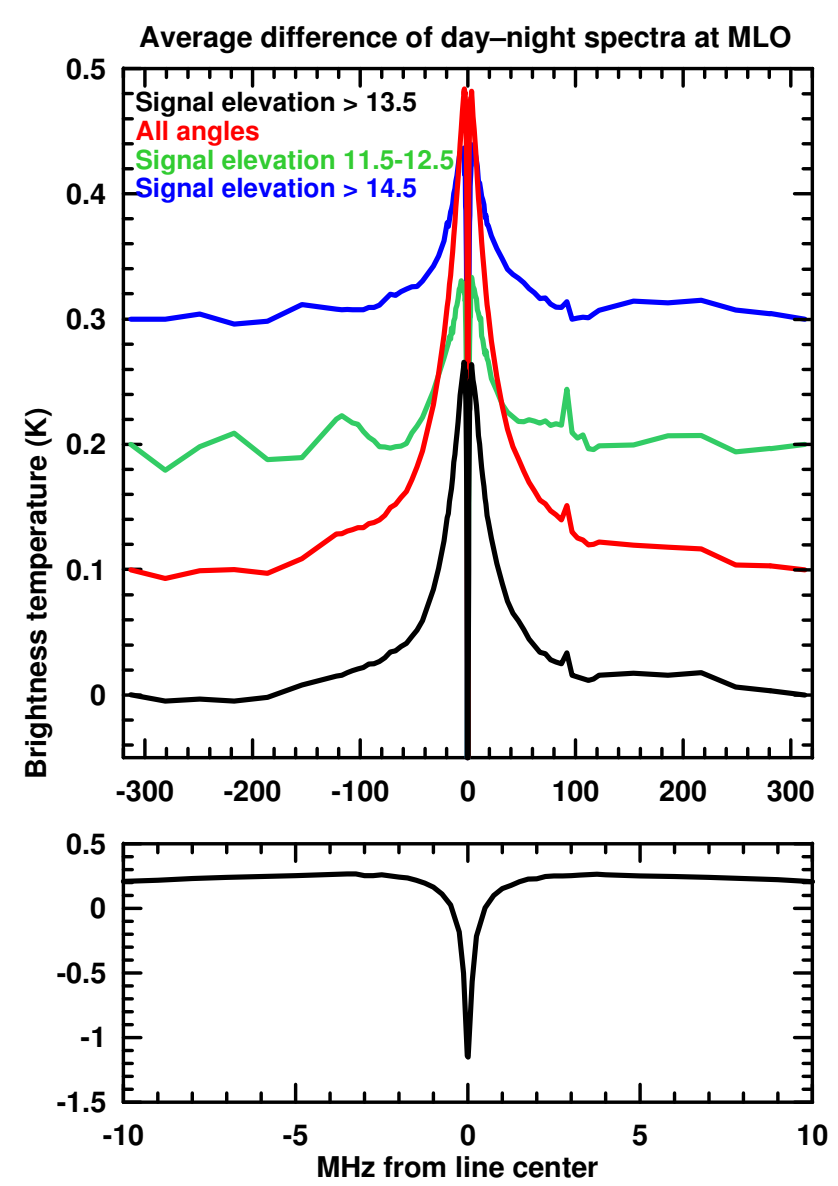

Figure 3. The top panel displays difference spectra corresponding to the difference profiles shown in Fig. 2. The nighttime reference spectrum is subtracted from the daytime spectrum in each case. The abscissa is expressed in units of brightness temperature in kelvin. The ordinate is expressed as an offset from the ozone line center frequency $(110836.04 \mathrm{MHz})$. The elevation angle ranges are indicated in the panel. The black spectrum corresponds to the selected temperature control led data with elevation angles $>13.5^{\circ}$. Each of the colored spectra has been offset upward by $0.1 \mathrm{~K}$ from the one below it for clarity, and correspond to the like-colored profiles in Fig. 2. The bottom panel displays the very narrow negative central feature in the black spectrum in the top panel with an expanded frequency scale and a compressed intensity scale.

profile in Fig. 2. Such features are commonly seen in spectra produced by instruments like the MWR due to the presence of an unintended interferometer in the signal path between the sky and the input to the receiver electronics, caused by weak reflections at devices in this path. The red spectrum is obtained when no restrictions are placed on the elevation angle. It contains a weak artifact like that seen in the green spectrum. It is smaller still in the black spectrum. The blue spectrum shows that the phase of the quasi-sinusoidal feature is substantially changed if the minimum elevation angle is raised to $14.5^{\circ}$. Such phase shift occurs when the spacing between the reflecting devices in an interferometer is changed, 
and is reasonable given the system window configuration, which is shown in Parrish (1994).

We believe that the best estimate of the day-night MWR difference profiles is obtained by selecting data that are taken both at a room temperature within $\pm 1.2^{\circ} \mathrm{C}$ of the thermostat setting and at elevation angles $>13.5^{\circ}$ because the temperature constraint minimizes the potential impact of diurnal room temperature variations on the measurements, and the angle constraint minimizes both the known artifacts in the difference spectrum shown for that angle range in Fig. 3 and the maxima and minima in the corresponding difference profile in Fig. 2. We use data selected in this manner for the work presented in the remainder of this paper.

\section{Comparison of MWR and satellite measurements}

We have compared difference profiles (e.g., day minus night) derived from the MWR data with those derived from several satellite-borne instruments to evaluate the consistency of these data sources. The satellite instruments are: Aura-MLS (Waters et al., 2006; Froidevaux et al., 2008), UARS-MLS (Barath et al., 1993; Froidevaux et al., 1996; Livesey et al., 2003), three Solar Backscatter Ultraviolet (SBUV/2) instruments aboard NOAA operational satellites (Frederick et al., 1986), and SMILES (Kikuchi et al., 2010).

Figure 4 compares daytime minus nighttime profiles measured with the MWR with those measured with Aura-MLS. This instrument measures the emission spectrum of a rotational transition of ozone at $243.6 \mathrm{GHz}$. We obtained the version 3.3 data from the Goddard Earth Sciences Data and Information Services Center (hereafter GES DISC); they are described in Livesey et al. (2011). Aura is in a sun-synchronous orbit; we use measurements made when it passes over MLO (in the early afternoon from 12:36 to 13:36 LST and at night from 01:36 to 02:36 LST). We calculated individual difference profiles for each day when there was a daytime profile and a nighttime profile within $15 \mathrm{~h}$ of each other, and within $1^{\circ}$ latitude and $6^{\circ}$ longitude of MLO. These profiles were averaged for the indicated seasons from the beginning of Aura-MLS measurements in August 2004 through March 2013. The MWR profiles were generated from MWR data that were selected as described previously, taken within a half hour of the MLS day and night overpass times, and were within $15 \mathrm{~h}$ of each other. There were 127 such measurement pairs in summer, 119 in autumn, 120 in winter, and 104 in spring. We did not select an AuraMLS pair that matched each MWR pair in time. The number of Aura measurements per unit time varies negligibly during the comparison period and there are no substantial gaps in the MWR measurements, so it is unlikely that a selection effect is introduced in the absence of any control on the difference in dates between the Aura-MLS and MWR measurements. The Aura-MLS data (red) were convolved with the MWR averaging kernels as described in Connor et al. (1995) to make them directly comparable in terms of vertical resolution. The differences between the original and convolved Aura-MLS data are typically $<1 \%$ below $1 \mathrm{hPa}(\sim 48 \mathrm{~km})$. Above this level, some differences are larger than the two standard deviation statistical error bars. We have included the dashed blue profiles derived directly from original Aura-MLS data in Fig. 4 to demonstrate these effects.

Differences between the MWR and Aura-MLS profiles in Fig. 4 are $<0.7 \%$ between 30 and $3 \mathrm{hPa}(\sim 24$ and $40 \mathrm{~km})$ when averaged over all seasons. Below and above these levels the Aura-MLS values increase with respect to the MWR values. The differences reach $\sim 1 \%$ at 56 and $2 \mathrm{hPa}(\sim 20$ and $43 \mathrm{~km}$ ) on average. Because their maximum differences do not consistently occur at a particular altitude, they will tend to be smoothed out in an all-season average. The largest bias, $\sim 3 \%$, is seen in winter between 1.3 and $0.8 \mathrm{hPa}(\sim 46$ and $50 \mathrm{~km}$ ). This apparent bias may be partially due to statistical fluctuations. Around $0.6 \mathrm{hPa}(\sim 52 \mathrm{~km})$ both the AuraMLS and MWR profiles show a progression of decreasing day-night ozone differences from summer though winter, with recovery in the spring.

The Aura-MLS day minus night profiles in Fig. 4 vary little with season, $<1 \%$, below $1 \mathrm{hPa}$. The MWR profiles vary more, lie above the Aura-MLS profiles at some altitudes but below at others, and the pattern differs from season to season. This pattern in the MWR profiles may superficially appear to be similar to the patterns in MWR profiles affected by systematic errors shown in Fig. 2. However, the major component of the fluctuations in the Fig. 4 profiles is statistical in nature. We determined this by extending the beginning of the averaging period back to August 1995 to substantially increase the number of profiles in the averages (not shown). As expected for statistical fluctuations, we found that the amplitude of the profile fluctuations decreased, going approximately as the inverse square root of the number of profiles contained in the averages, when compared to the averages shown in Fig. 4.

We compared day minus night measurements made with the SMILES, Aura-MLS, and MWR instruments. SMILES began operating on 12 October 2009 and failed on 21 April 2010. Its profiles are derived from spectral measurements of a rotational transition of ozone at $625.4 \mathrm{GHz}$. Its ozone measurements were made in either of two receiver configurations, known as "Band A" and "Band B"; these are described in Kikuchi et al. (2010). We excluded from the average difference profiles described below individual profiles in which the daytime measurement was made with the instrument set up in Band A while the nighttime measurement was made in Band B or vice versa; this was done to eliminate potential systematic effects that could otherwise appear. Validation of SMILES ozone data is described in Imai et al. (2013). The native units of the SMILES L2 version 2.1 data are mixing ratio vs. altitude. In this comparison, we use pressures supplied with the data for conversion to the mixing ratio vs. pressure native units of Aura-MLS and MWR. The pressure 

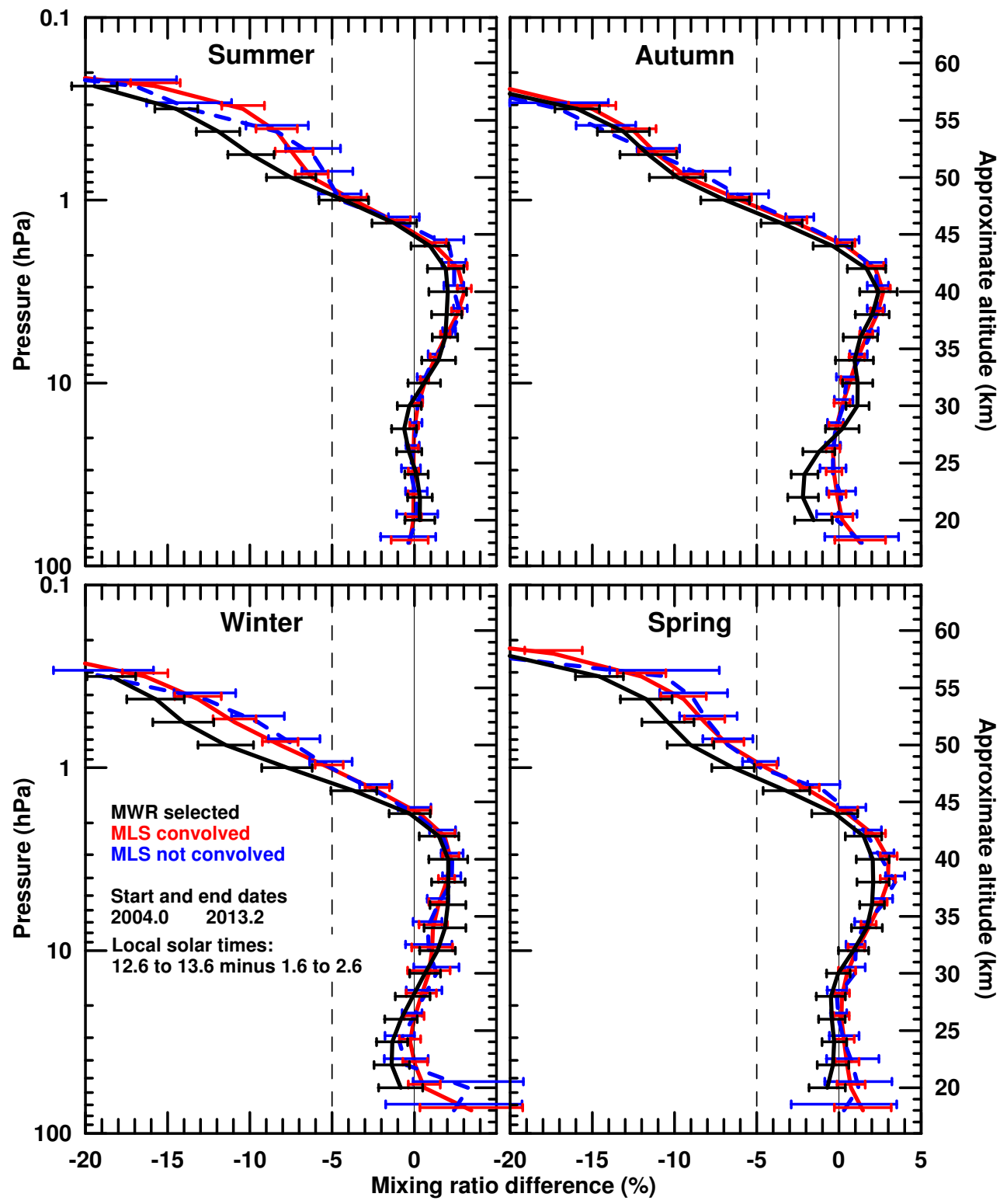

Figure 4. Day-night ozone differences as measured by Aura-MLS and by the MWR at Mauna Loa. The MWR measurements are shown in black and were derived from selected data as described in Sect. 2. The Aura-MLS measurements shown in red have been convolved with the averaging kernels of the MWR, while those shown as blue dashed lines were derived from the original data. Measurements from each instrument have been averaged over the indicated period. The dates and times associated with the observations, the normalization technique, and the method of calculating and displaying the error bars are as described in the caption for Fig. 1.

values included with the SMILES data are derived, assuming hydrostatic equilibrium, from atmospheric temperature profiles also measured by SMILES (Imai et al., 2013). The instrument overpasses MLO twice each day, cycling through $24 \mathrm{~h}$ every $\sim 60$ days. It is therefore possible to obtain profile differences between pairs of times separated by roughly $12 \mathrm{~h}$, although at some times of day there are very few measurements. For the time ranges 11:36 to $15: 36$ and 23:36 to 03:36 LST at Mauna Loa, there were six groups of SMILES day-night measurement pairs, approximately equally spaced between October 2009 and March 2010. The minimum number of pairs was four per group, the maximum 14, and the average eight. The time ranges were chosen to maximize the number of SMILES pairs included in the average while also including the Aura-MLS overpass times. Figure 5 displays the day-night difference profiles derived from these measurement pairs, and likewise the Aura-MLS and MWR profiles. The MWR and Aura-MLS profiles were also averaged over the time and date ranges indicated above. 


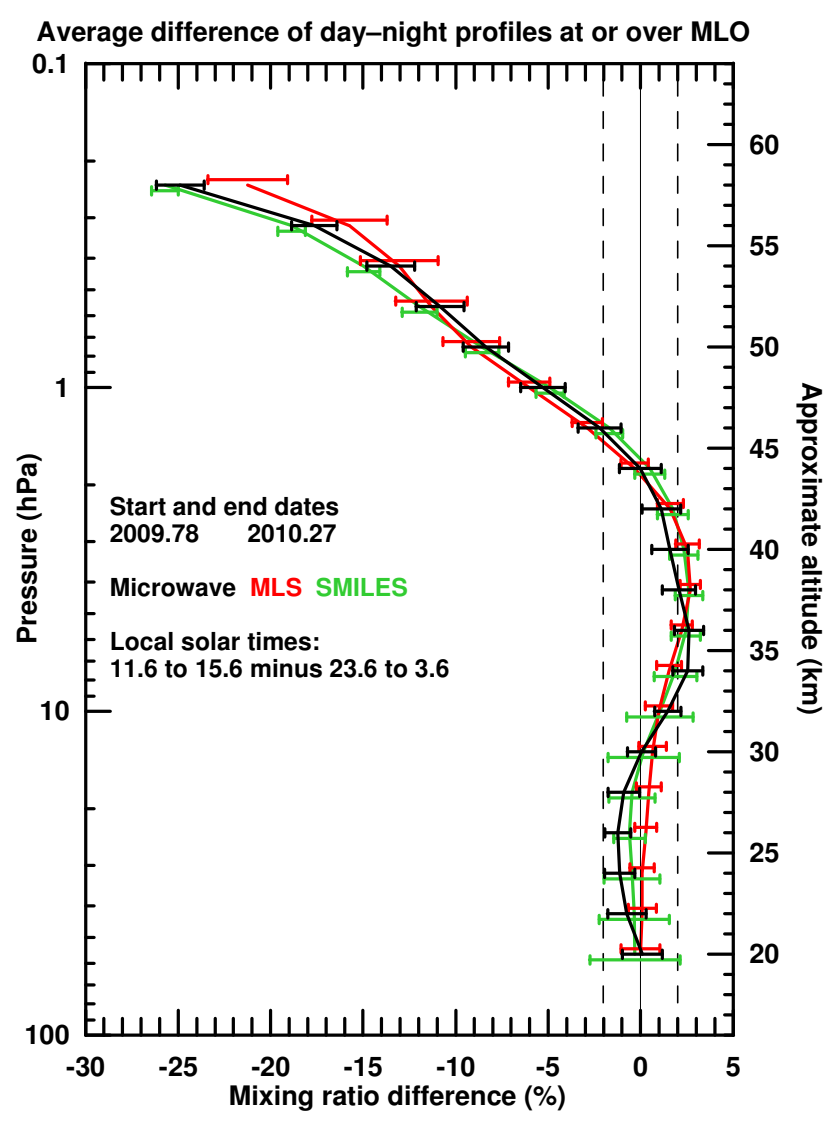

Figure 5. Afternoon-night differences derived from SMILES (green), Aura-MLS (red), and MWR selected data (black) at Mauna Loa. The SMILES and Aura-MLS measurements have been convolved with the MWR averaging kernels. All measurements have been averaged over the indicated SMILES observing period. The afternoon SMILES and MWR measurement pairs were averaged over the periods $11: 36$ to $15: 36$ and the nighttime over $23: 36$ to 03:36 LST. The time ranges for MLS are narrower, 13:00 to 13:48 and 01:30 to 02:24 LST because Aura is in a sun-synchronous orbit. Individual measurements were averaged over the period 12 October 2009 to 9 April 2010 and combined as described in Sect. 2.1 to make these profiles. Error bars are calculated and displayed as described in the caption for Fig. 1.

The day minus night profiles shown in Fig. 5 from the three instruments agree within $1.5 \%$ from 56 to $0.4 \mathrm{hPa}(\sim 20-54 \mathrm{~km})$. In this range, the differences between seventy-seven percent of the total number of MWR and Aura-MLS pressure-corresponding data point pairs are $<1 \%$, as defined in Sect 2.1. Likewise, seventy-seven percent of the MWR-SMILES differences and fifty-five percent of the AURA-MLS minus SMILES differences are $<1 \%$. Further, all of the individual profiles lie within $1 \%$ of the average of the three profiles up to $0.7 \mathrm{hPa}(\sim 50 \mathrm{~km})$. The MWR profile mostly lies between the SMILES and AuraMLS profiles, so the difference between the MWR profile and the average of the SMILES and Aura-MLS profiles is
$<1 \%$ from 56 to $0.3 \mathrm{hPa}(\sim 20$ to $56 \mathrm{~km})$. All three profiles peak at $\sim 2.5 \%$ between 5 and $3 \mathrm{hPa}(35$ and $40 \mathrm{~km})$. Above $0.4 \mathrm{hPa}(\sim 54 \mathrm{~km})$, the differences between Aura-MLS and the other two instruments are $2 \%$ or more, with the AuraMLS values less negative, as in Fig. 4. The MWR minus Aura-MLS differences are smaller than they are in the winter panel of Fig. 4, because they are being averaged over all seasons. They are statistically significant only at $0.2 \mathrm{hPa}$ $(\sim 58 \mathrm{~km})$.

There are small differences between Figs. 4 and 5 above $3 \mathrm{hPa}(\sim 40 \mathrm{~km})$. These may result from a selection effect given the fact that the SMILES and MWR profiles in Fig. 5 were averaged over four hour time blocks while the Aura-MLS measurements lie within one hour blocks. We attempted to test for such an effect by calculating a MWR profile (not shown in the figure) where the data were averaged over just one hour centered on the MLS overpass times. The precision of this test was poor because the MWR profile is made up from only 15 measurement pairs. Nonetheless, this profile lies within $2.5 \%$ of the MWR and Aura-MLS profiles in Fig. 5, and the differences are not statistically significant.

In Fig. 6 we show comparisons for another time period, morning-night, using data from UARS-MLS, MWR, and SMILES. UARS-MLS profiles are derived from the spectra of a rotational ozone transition at $206.13 \mathrm{GHz}$. The data were obtained from GES DISC and are described in Livesey et al. (2003). To optimize the number of morning measurements we used, for all instruments, data between 07:36 to 10:36 LST for morning and 21:36 to 00:36 LST for night. Coincidence in time between the satellite and MWR measurements is unfortunately an issue. UARS-MLS passed over MLO at varying times, but made very few morning measurements after the MWR began operating in 1995; most of the UARS-MLS measurements were made in the September 1991 to May 1994 period, while the MWR data are from July 1995 up to January 1998. The latter date was chosen to correspond to the date when UARS-MLS measurements ended. The MWR was operating throughout the period when SMILES was making measurements. There are six groups of SMILES difference profiles during this period, with a total of 27 profiles. The figure shows a second MWR profile that covers the period 19 October 2009 to 20 April 2010 to cover the period of measurements included in the SMILES profile.

All four profiles in Fig. 6 have similar shapes and these are noticeably different than the profiles in Fig. 5. In Fig. 6 the values are positive between about 3 and $1.3 \mathrm{hPa}(\sim 40$ to $46 \mathrm{~km}$ ), while in Fig. 5 the values are positive between about 10 and $2 \mathrm{hPa}(\sim 32$ to $43 \mathrm{~km})$. However, the differences between profiles are larger than they are in Fig. 5. We compared the satellite (UARS-MLS or SMILES) values and their corresponding MWR values, and found that only forty percent of the total number of differences between pressurecorresponding data points are within $1 \%$ of each other. Seventy percent are within $1.5 \%$, and ninety percent are within $2 \%$, and all are within $2.1 \%$. Even though the SMILES data 


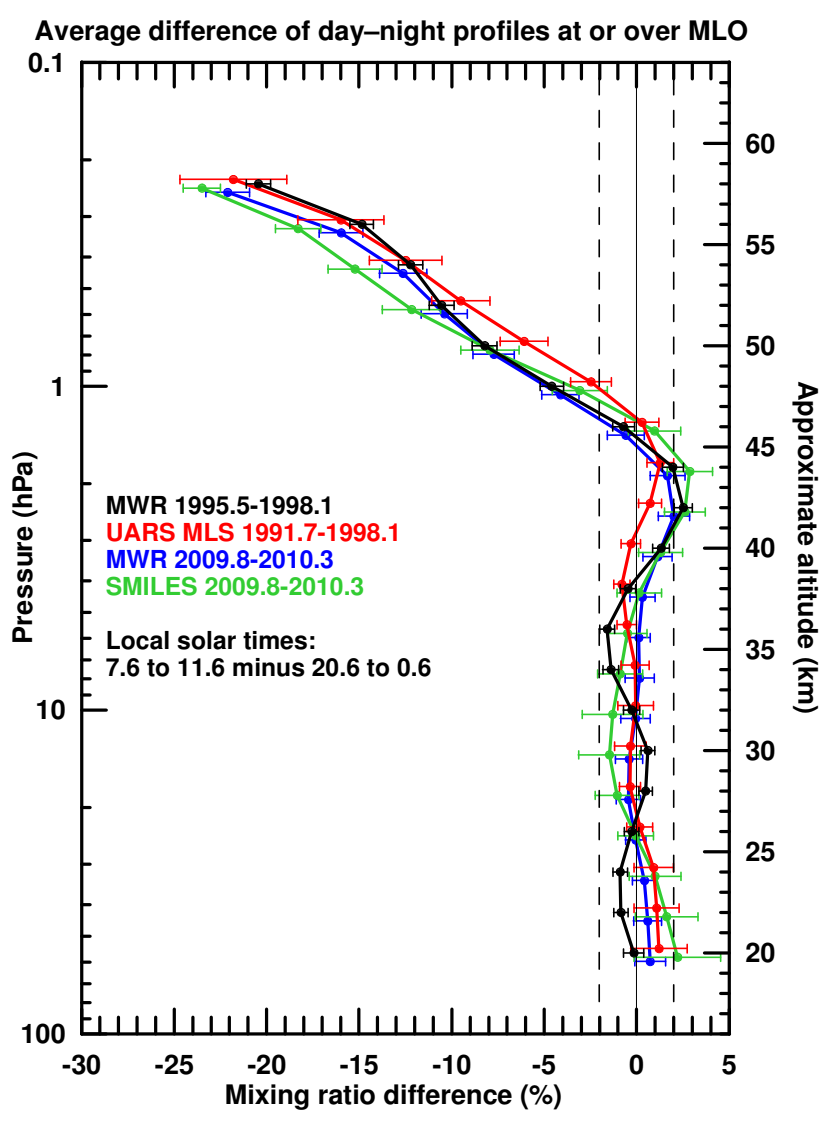

Figure 6. Average differences between morning (07:36 to 10:36 LST) and nighttime reference (21:36 to 00:36 LST) from UARS-MLS, SMILES, and MWR data. The data were normalized as described in Sect. 2.1. The SMILES profile shown in green and MWR profile shown in blue were averaged over the period 12 October 2009 to 20 April 2010. The MWR profile shown in black was averaged over January 1995 to February 1998; the UARS-MLS profile shown in red over September 1991 to February 1998. The SMILES and UARS-MLS data have been convolved with the MWR averaging kernels. The error bars are calculated and displayed as described in the caption for Fig. 1.

were taken $\sim 15$ years later than the UARS-MLS data, agreement of the day minus night profile values for this pair is similar to those just described. Thirty-five percent of the differences are within $1 \%, 65 \%$ are within $2 \%$, and all are within $2.7 \%$. The August 1995 to January 1998 MWR profile corresponding to the UARS-MLS profile is alternately lower and higher than the latter up to $1.8 \mathrm{hPa}(\sim 43 \mathrm{~km})$. The character of these fluctuations is similar to those shown in Fig. 2. Possibly there is a systematic contribution of the order of $1 \%$ to the profile during this early period that is not yet understood. These fluctuations therefore should not be regarded as reliable pending further investigation.

In Fig. 7, we have constructed difference profiles from the measurements of pairs of SBUV/2 instruments on NOAA operational satellites that pass over MLO at different times

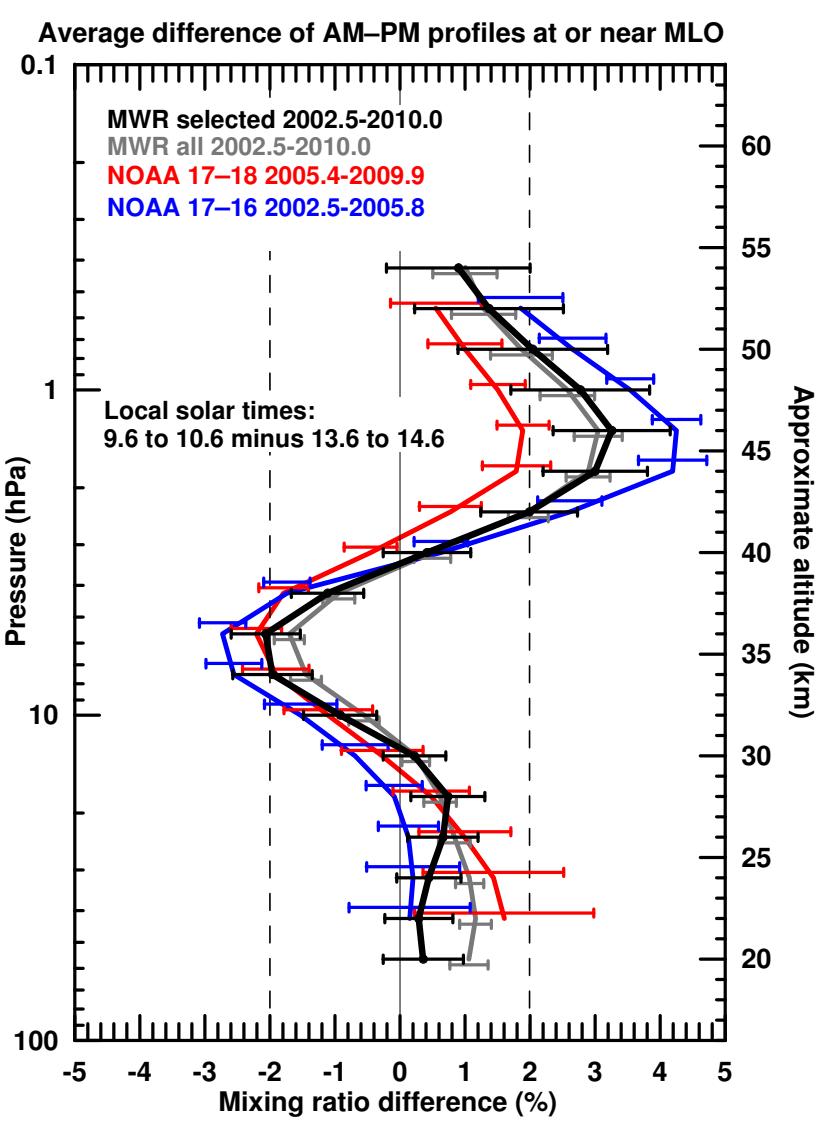

Figure 7. Percentage differences between morning and afternoon ozone profiles. The morning satellite profiles are all from NOAA17 SBUV/2 measurements, averaged between 09:36 and 10:36 LST. The reference afternoon profiles are from NOAA-18 (red) or NOAA-16 (blue) and were averaged from 13:36 to 14:36 LST. They were subtracted from the morning profiles and normalized as described in Sect. 2.1. Differences between morning and afternoon (reference) MWR measurements taken during the same time blocks are shown for comparison in black (selected data) or gray (all data). The data used for the NOAA-17 and 16 profile were averaged from July 2002 to December 2005; those for the NOAA-17 and 18 profile were averaged from June 2005 to November 2009. MWR data were averaged from July 2002 to December 2009. Error bars are calculated and displayed as described in the caption for Fig. 1. The SBUV/2 data have not been convolved with the MWR averaging kernels because the resolutions of the two instruments are similar.

of the day. We derived the SBUV/2 profiles from the March 2013 reprocessing of version 8.6 data. In this reprocessing, the NOAA-16 SBUV/2 time-dependent calibration is based on the Antarctic snow/ice radiance approach described in DeLand et al. (2012), due to problems with the behavior of the onboard calibration system previously used to characterize that instrument (M. T. DeLand, personal communication, 2013). This procedure was previously developed and used for the NOAA-17 and NOAA-18 calibration in the v8.6 data. The NOAA-17 overpass times fell between 09:36 and 
10:3 LST between 2002 and 2009, and the afternoon overpass times of NOAA-16 and NOAA-18 fell between 13:36 and 14:36 LST for a year or more during those years. The NOAA-17 minus NOAA-18 profile (red) and the NOAA17 minus NOAA-16 profile (blue) are compared in the figure with the MWR profile (black, selected data) for 09:36 to 10:36 LST minus its profile for 13:36 to $14: 36 \mathrm{LST}$. The shapes of these profiles are very similar. Seventy-five percent of the total number of MWR-SBUV/2 differences between pressure-corresponding data points are $<1 \%$. The exceptions are in the 1 to $2 \mathrm{hPa}$ range. All are $<1.5 \%$. The points on the average of the two MWR-SBUV/ 2 profiles are all $<1 \%$, with a slight positive bias of $\sim 0.5 \%$ from $\sim 20$ to $2 \mathrm{hPa}$.

In addition to the black profile derived from selected MWR data, Fig. 7 includes a gray profile made from MWR data without limitations on temperature or elevation angle. The differences are $<0.6 \%$ above $24 \mathrm{hPa}(\sim 26 \mathrm{~km})$. This result suggests that the MWR measurements are less affected by time-dependent systematic errors during the day than during the day-night transition.

\subsection{Summary of comparisons}

We have calculated profile differences in ozone expressed in normalized units as described in Sect. 2.1 between two times of day at or over MLO from measurements made by MWR, Aura-MLS, UARS-MLS, SMILES, and two pairings of SBUV/2 instruments. These results cover the time periods of afternoon-night, morning-night, and morning-afternoon. The MWR, Aura-MLS, and SMILES afternoon-night profiles shown in Fig. 5 are mutually consistent, each agreeing with any other to within a maximum of $1.5 \%$ and typically within $1.2 \%$ up to $0.6 \mathrm{hPa}(\sim 52 \mathrm{~km})$. If we take the average of these three profiles to be the best available estimate of the true difference profile over this time interval we find that all individual profiles lie within $1 \%$ of it over the above altitude range. The comparisons between the morning-afternoon profile measured with the MWR and those measured with pairs of SBUV/2 instruments as shown in Fig. 7 are also consistent, with differences of $<1 \%$ from 42 to $0.6 \mathrm{hPa}(\sim 22$ to $52 \mathrm{~km})$. The morning-night comparison using MWR, UARS-MLS, and SMILES, however, is poorer. Above $1 \mathrm{hPa}$, differences between the SMILES profile and the corresponding MWR profile can reach $2.7 \%$, and differences between the UARS-MLS profile and its corresponding MWR profile can reach $2.2 \%$. However, the differences in both cases are typically $<1.7 \%$.

\subsection{Uncertainty in MWR measurements}

The only tests we have of any diurnally varying systematic errors that may remain in the MWR measurements come from the character of the errors seen in Fig. 2 and the comparisons discussed in Sect. 3.0. If, for the purpose of discussion, we take the average of the afternoon-night Aura-MLS and SMILES profiles shown in Fig. 5 as a reference, we find that the MWR profile differs from it by $<1 \%$ up to $0.3 \mathrm{hPa}$ $(\sim 56 \mathrm{~km})$. So, there is no evidence from these comparisons for MWR systematic errors $>1 \%$ during the afternoon-night interval. Likewise, if we take the average of the two SBUV/2 profiles in Fig. 7 as a reference for morning-afternoon differences, we find that the MWR profile differs from it by $<1 \%$ from 42 to $0.6 \mathrm{hPa}(\sim 22-52 \mathrm{~km})$. However, a similar procedure for the morning-night profiles in Fig. 6 yields a worse result. We computed the difference between the SMILES profile and its corresponding MWR profile in Fig. 6, and for the UARS-MLS profile and its corresponding MWR profile. We take the average of these as the difference between the MWR results and combined SMILES and UARS-MLS results. The absolute values of points on this profile are $<1.7 \%$ up to $0.2 \mathrm{hPa}(\sim 58 \mathrm{~km})$ and $85 \%$ of them lie within $1.5 \%$. Alternatively, the morning-night differences can be estimated by combining the afternoon-night comparison using Aura-MLS and SMILES with the morning-afternoon comparison using SBUV/2 data, both of which show differences $<1 \%$. Because this procedure involves the uncertainties in both comparisons, the estimated combined uncertainty is larger than the individual ones by a factor of $2^{0.5}$, assuming that the morning-night and morning-afternoon validation resources are statistically independent. This process yields an uncertainty estimate of $1.4 \%$. Given this value, and the fact that eighty-five percent of the total number of direct morning-night differences are within $1.5 \%$, we believe it is reasonable to take $1.5 \%$ as the MWR systematic limit for the morning-night interval.

\section{Model comparison and discussion}

We display measured and model calculated ozone values for each hour of the day at 18 pressure levels for summer (June, July, and August) in Fig. 8 and for winter (December, January, and February) in Fig. 9. The measured values are based on the selected MLO MWR data, which have been binned hourly and averaged over the indicated months in all years from 1995 to 2013 to minimize statistical fluctuations. The model simulations use chemical and greenhouse gas conditions for 2005. Both the measurements and the modeled results have been normalized to their midnight values.

The model results are from the so-called STRATTROP version of the Goddard Earth Observing System Chemistry Climate Model (GEOSCCMSTRATROP). It couples the comprehensive stratospheric/tropospheric chemistry package developed within the Global Modeling Initiative (GMI) (Duncan et al., 2007; Strahan et al., 2007; Oman et al., 2011) to version 5 of the GEOS GCM (Rienicker et al., 2011). It does not include a full representation of mesospheric processes but the processes controlling ozone in the middle to upper stratosphere are complete and the model diurnal cycle is thought to be realistic at altitudes $<\sim 52 \mathrm{~km}(0.5 \mathrm{hPa})$. 


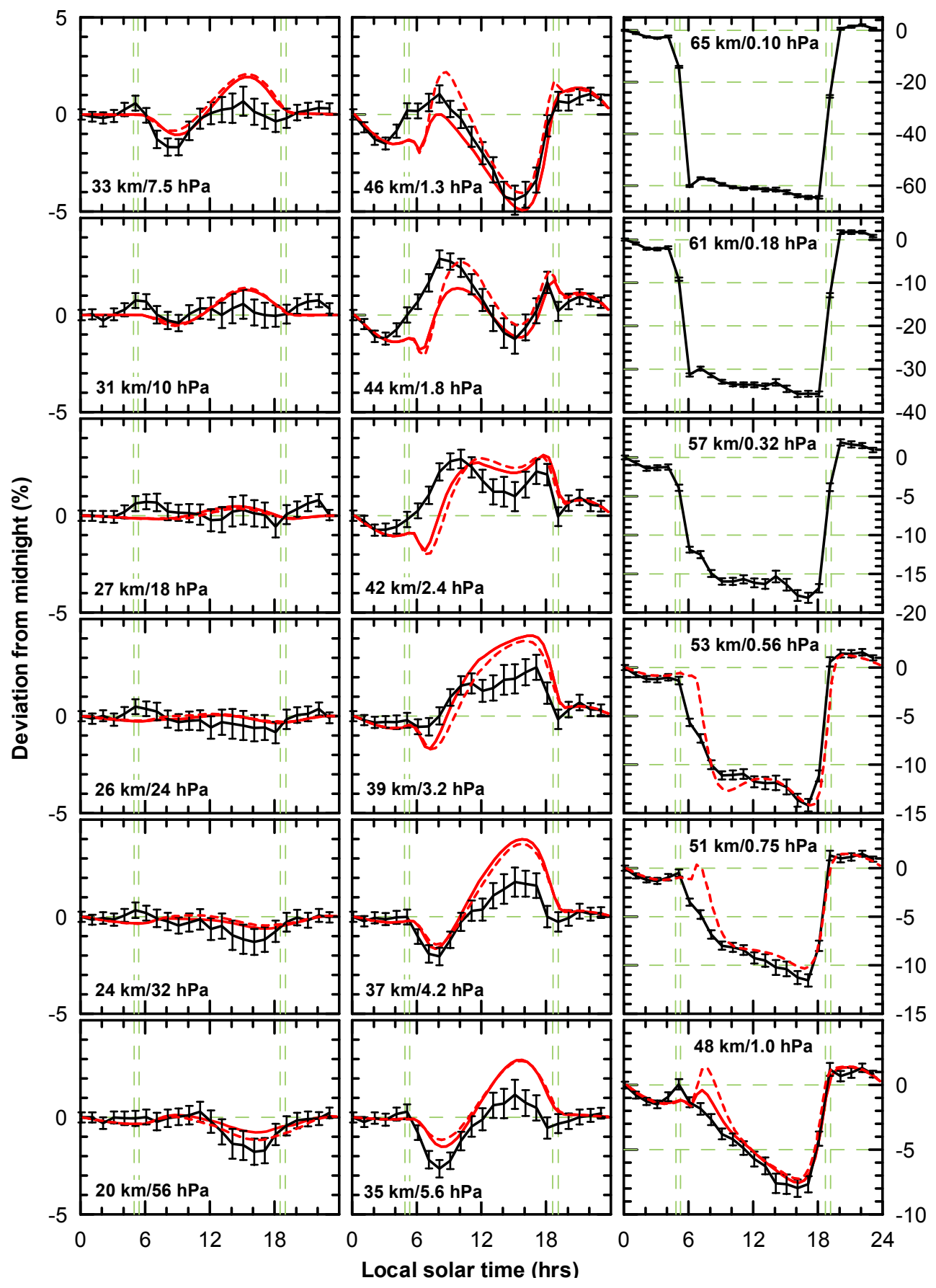

Figure 8. Measured and modeled ozone values for each hour of the day in summer (June, July, and August), normalized to the corresponding midnight values. Measured values (black) are derived from selected MWR data, averaged over the summer months from 1995 to 2013 , at pressure levels between $56 \mathrm{hPa}$ (bottom left panel) and $0.1 \mathrm{hPa}$ (top right panel). The scales for the panels from 1 to $0.1 \mathrm{hPa}$ are given on the right hand ordinates; the scales for all others are given on the left hand ordinates. All values have been normalized to the midnight value as described in Sect. 2.1. Two standard deviation statistical error estimates described in the text are shown as error bars. The original output

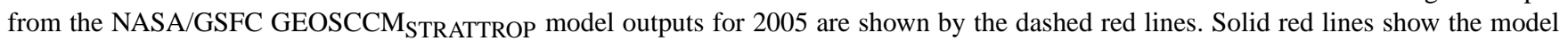
outputs after convolution with the MWR averaging kernels. Dashed green vertical lines indicate the earliest and latest sunrise times at the given altitude. 


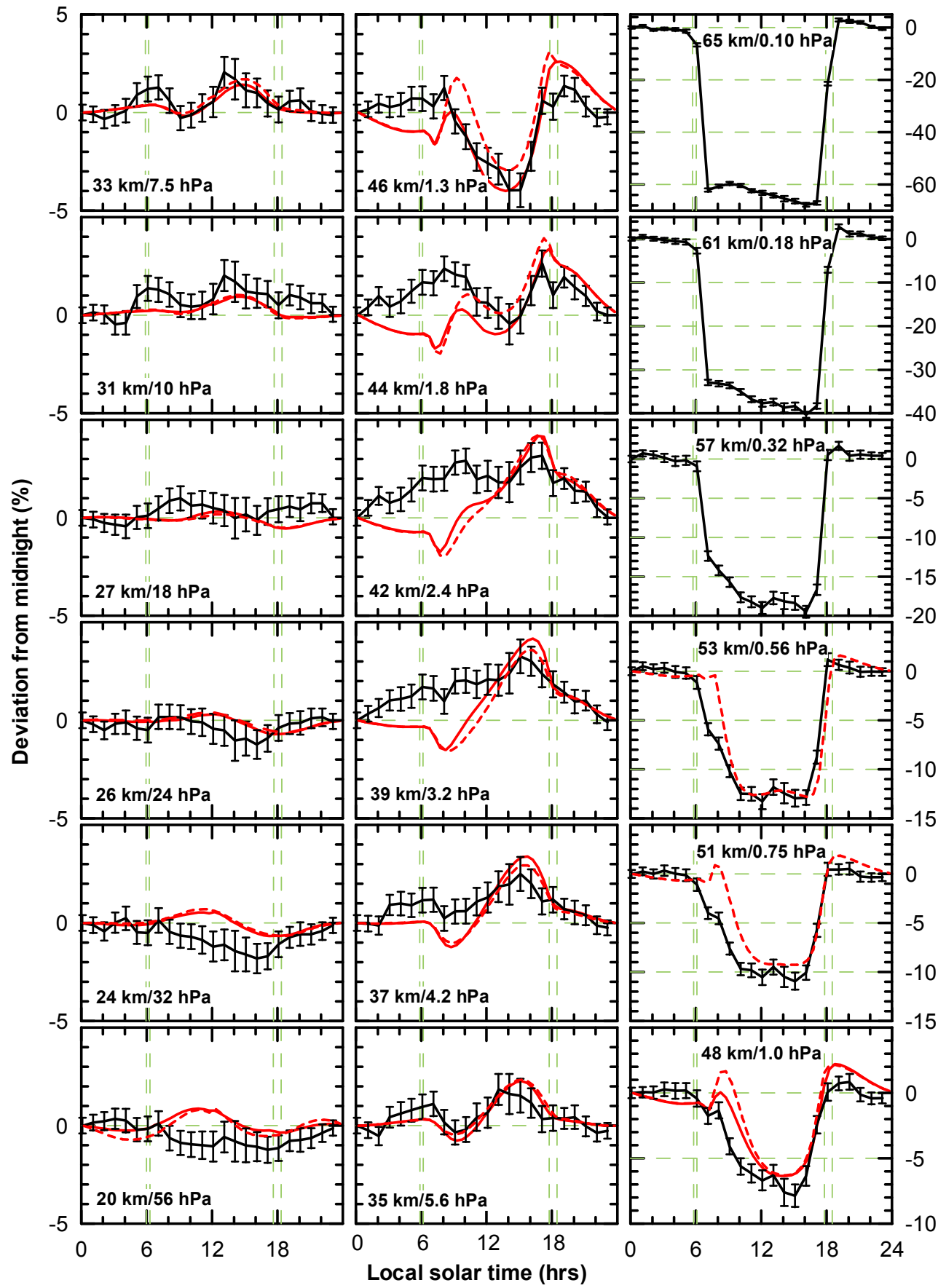

Figure 9. Measured and modeled ozone values as in Fig. 8 except for winter (January, February, and March).

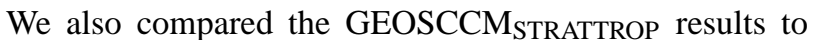
those from the GEOSSCCM uses the stratospheric chemistry package developed by Douglass and Kawa (1999). It was extensively evaluated as part of the Stratospheric Processes And their Role in Climate (SPARC) Chemistry Climate Model Validation (CCMVal) project (SPARC CCMVal, 2010), and performed well in the photolysis computation and representation of radicals, both of direct relevance to this comparison. Because differences between the outputs from these two models vary from zero to a maximum of $1 \%$ below $1 \mathrm{hPa}$ at $20^{\circ} \mathrm{N}$, we only show results from STRATTROP.

The MWR vertical resolution is poorer than that of the models, which have $1 \mathrm{~km}$ level spacing. We convolved the model output with the microwave averaging kernels to minimize resolution effects on the MWR-model comparison. 


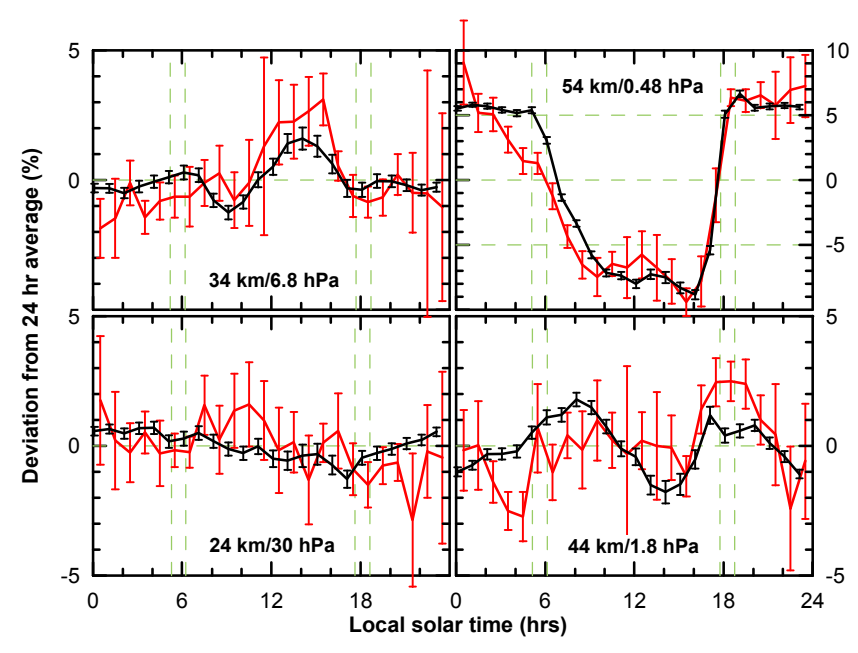

Figure 10. Ozone values as measured by SMILES (red line) and MWR (black line) for each hour of the day, normalized to the corresponding average of measurements over all $24 \mathrm{~h}$. The SMILES measurements were taken over a zonal band from $15^{\circ}$ to $25^{\circ} \mathrm{N}$. The dashed green vertical lines indicate sunrise and sunset times at $20^{\circ} \mathrm{N}$. Two standard deviation statistical error estimates are shown as error bars. See text for other details.

Above $0.5 \mathrm{hPa}$, which is outside the primary domain of the model, we truncated its output and spliced on a reasonable profile, namely the MWR a priori profile over the pressure range 0.5 to $0.01 \mathrm{hPa}$, before performing the convolution. We note that the resolution effects are small even when the model output is compared directly with the MWR measurements. The dashed lines in Figs. 8 and 9 display the original (unconvolved) output from the GEOSCCMSTRATTROP model. The differences between the original and convolved model outputs are small compared to the experimental errors except around $1-2 \mathrm{hPa}$.

The major features in Figs. 8 and 9 have been previously discussed in the literature. The well-known mesospheric variations are primarily driven by the oxygen chemistry described in Sect. 1. Because the rate of reaction (3) is proportional to air density, the amplitude of the mesospheric cycle is inversely proportional to density as described in, e.g., Connor et al. (1994) and Haefele et al. (2008). In the 3-7 hPa region the model output displays a minimum at $\sim 1 \mathrm{hr}$ after sunrise followed by increasing ozone values through the day, peaking in the afternoon around 16:00 LST. The measurements exhibit the increase through the day after $\sim 08: 00$ LST and the peak at $\sim 16: 00$ LST. This was also observed by Haefele et al. (2008) who argue that the rising values through the day in this region are primarily due to daytime photolytic production of odd oxygen and the low $\mathrm{O} / \mathrm{O}_{3}$ ratio. Pallister and Tuck (1983) argue that the early morning minimum is due to the rapid photodissociation of $\mathrm{NO}_{2}$, which triggers the $\mathrm{NO}_{\mathrm{x}}$ catalytic cycle. Photodissociation of $\mathrm{NO}_{2}$ occurs at wavelengths which are not shielded by overlying ozone, so it occurs rapidly at sunrise. The measurements exhibit this feature up to $4 \mathrm{hPa}$. Between 3 and $1 \mathrm{hPa}$ the modeled feature is not expected to be clearly visible in the measurements because it is smaller than the measurement errors. However, there is a hint of it in the winter data.

In the region between 1 and $3 \mathrm{hPa}$, the ozone diurnal time dependence exhibits a complex transition between daytime depletion and enhancement. In the afternoon and evening, the measurements and models agree to $<1 \%$ at most levels in both winter and summer. The agreement includes some small details, such as the maximum at $1.8 \mathrm{hPa}$ shortly before sunset. They do not agree as well in the period between midnight and noon, particularly in winter, when the measurements can be as much as $3.5 \%$ higher than the model output at $\sim$ 08:00 LST largely due to a differing evolution of ozone in the pre-dawn hours. We believe that these modelmeasurement differences are not caused by experimental errors. In the comparisons shown in Fig. 6, the morning-night differences from the MWR fell at or between those from UARS-MLS and SMILES. Similarly, in Fig. 7, the morningafternoon MWR differences fell between the NOAA-17 minus NOAA-16 SBUV/2 and NOAA-17 minus NOAA-18 SBUV/2 differences. Although the scatter between results in each of these cases is larger than those displayed in Fig. 5, the MWR results are not outliers. These two cases, especially when taken together, do not support a systematic MWR measurement error of the order of $2 \%$ in the 3.2 to $1.8 \mathrm{hPa}$ range. We also have inspected difference spectra for the month of March, similar to those shown in Fig. 3, and have found that they are qualitatively consistent with the pre-dawn increase described above. We note that the comparisons described in Sect. 3 do not directly cover the pre-dawn time period. However, we are not aware of any unresolved issues that would affect the measurements during this period. Our measurements therefore suggest that there is a process that enhances ozone values between 3 and $1 \mathrm{hPa}$ during pre-dawn and morning hours that is not captured in the model.

Below the $10 \mathrm{hPa}$ pressure level, the modeled variations are small, typically $<1 \%$. In winter, a small maximum that occurs in early afternoon shifts earlier in the day as altitude decreases, and it is followed by a small minimum in the late afternoon in the lower stratosphere. A similar pattern is displayed in summer, but the amplitudes of the variations are less. Haefele et al. (2008) and Sakazaki et al. (2013) attribute such variations to vertical motions due to atmospheric tides and the sharp vertical ozone gradient in this region. The summer measurements are generally in phase with the corresponding model outputs, while the winter measurements are either not in phase or do not exhibit the small daytime maximum. However, this apparent summer/winter difference should be considered with caution because the measured variations are not substantial compared to the experimental errors. 
Similar comparisons between models and recent groundbased microwave measurements made at Payerne and Bern, Switzerland $\left(47^{\circ} \mathrm{N}\right)$ have been reported by Haefele et al. (2008) and Studer et al. (2013), respectively. Comparisons between their results and ours must be viewed with caution because there is a substantial difference between the latitudes of the two sites, different models are used for each study, and the averaging kernels of the Swiss instruments are wider than those of the MLO MWR. That said, we note that the lower stratospheric model outputs shown in these papers (27 and $23 \mathrm{hPa}$, respectively) are similar to our model outputs at the corresponding levels, and the model-measurement differences are not significant, given the measurement errors, except for the summer measurements shown in Fig. 6 in the former paper. We believe it is reasonable to treat this result as an outlier, as their and our measurements are otherwise reasonably consistent with the corresponding model results. None of these measurements are good enough to definitively distinguish between model results, given the small values in the latter.

The summertime Haefele et al. (2008) model results at $3 \mathrm{hPa}$ (except for Solar Climate Ozone Links (SOCOL)) and the Studer et al. (2013) model results at $6 \mathrm{hPa}$ are qualitatively similar to ours in that they display the minimum shortly after sunrise followed by increasing values until the later afternoon. The amplitude of the diurnal waveform in the former paper is about $50 \%$ larger than in ours while it is about the same in the latter paper. In both of these cases, the amplitude of the measured waveform is larger than the modeled one by a factor of $\sim 1.3$. Fig. 5 in the latter paper includes data points from Aura-MLS measurements at $\sim 01: 00$ and 13:00 LST; these are consistent with their model results but not with their measurements. The minimum shortly after sunrise is not observed in either case, while it does appear in our measurements. Their measured values increase before sunrise and decrease after sunset, while their model results do not. This behavior is similar to that seen in our wintertime but not our summertime measurements at higher altitudes (corresponding pressures between 3 and $2 \mathrm{hPa}$ ) in Fig. 8. So, their results also suggest that situations exist where diurnal ozone values actually increase before dawn in the 1 to $6 \mathrm{hPa}$ range, but they do not directly confirm our result because of the differences between their work and ours regarding latitude and the models used.

Sakazaki et al. (2013) have presented comparisons between SMILES measurements and two models (Whole Atmosphere Community Climate Model (WACCM) and Model for Interdisciplinary Research on Climate (MIROC) version 3.2 chemistry transport model). They processed both the measured data and the model outputs in a self-consistent way to address the issue of the coupling between diurnal and seasonal variations in asynchronous satellite measurements described in Sect. 1. They averaged data over the zonal band from $10^{\circ} \mathrm{S}$. to $10^{\circ} \mathrm{N}$. and did not observe the pre-dawn ozone increase and the morning (08:00 LST) maximum at
$44 \mathrm{~km}$ that are shown in Fig. 9. This altitude region is especially interesting because it is where the discrepancy between our modeled and measured features is the largest. Part of the discrepancy between these results is due to the dependence of diurnal variations on latitude due to equatorial upwelling shown in their Fig. 6. We present Fig. 10 to compare MWR and SMILES measurements at the same latitude. The SMILES data have been averaged over a zonal band between $15^{\circ}$ and $25^{\circ} \mathrm{N}$. and processed as described in Sakazaki et al. (2013). This band has been limited to a width of $10^{\circ}$ to minimize coupling to the equatorial region, with the consequence that the errors are larger than those shown in Fig. 4 in their paper. While the SMILES measurements have not been convolved with the MWR averaging kernels, we believe that the changes caused by convolving them would not be substantive. The MWR values and associated errors are drawn from our data averaged from day 285 in October of each year to day 111 in April of the following year between 1995 and 2013. The errors are set at the $95 \%$ confidence level for statistical fluctuations. We note that we see similar but noisier features if we take the average only from 2009 to 2010 as a precaution to eliminate any influence of possible variations that only appear in years when SMILES was not operating. The anomalies are shown in the figure as a percentage difference from the ozone values averaged over all $24 \mathrm{~h}$ in both cases. The SMILES and MWR measurements mostly agree within the errors. The fact that the morning decrease in the SMILES values occurs about a half hour earlier than that of the MWR values at $54 \mathrm{~km}$ may be partially due to a weighting effect caused by the variable times of sunrise and sunset over the SMILES zonal band in the winter months. At $44 \mathrm{~km}$ the SMILES values are lower than the MWR values by $\sim 2 \%$ at 03:00 and 04:00 LST, and these differences are statistically significant. The SMILES values also appear to follow the GEOSCCM model more closely than the MWR values at this altitude. This discrepancy remains whether we use data selected as described in Sect. 2 or all of the data. We do not believe the discrepancy is due to a fundamental difference between SMILES and MWR measurements because they agree within $1 \%$ at $44 \mathrm{~km}$ when comparing SMILES overpasses at MLO as discussed in Sect. 3. Figure 6 therein clearly shows a morning maximum peaking at $42-43 \mathrm{~km}$ in both the SMILES and MWR profiles, and a smaller one in the UARS-MLS profile. Efforts to date to reconcile this discrepancy have not borne fruit. It may be that the discrepancy results from multiple causes involving both the SMILES and MWR measurement and analysis systems, which would make reconciliation difficult if not impossible to complete. 


\section{Conclusions}

We have developed measurements of the diurnal variations of stratospheric ozone over Mauna Loa, Hawaii from the original data produced by the NDACC microwave ozone profiling instrument (MWR) located there. We have attempted to maximize the accuracy of these relative diurnal measurements by studying the effects of diurnally varying environmental variables on the diurnal data and selecting data that meet criteria for signal beam elevation angle and diurnal building temperature limits developed from the study. We validated our diurnal data by means of intercomparisons of diurnal difference profiles between three instrument types: the MWR, satellite-borne microwave limb sounders (UARSMLS, Aura-MLS, and SMILES), and solar backscattered ultraviolet instruments (SBUV/2 on NOAA-16, 17, and 18). We considered three pairs of times. For afternoon-night, we found that the consensus between MWR, Aura-MLS, and SMILES is very good, with maximum profile differences between any pair of these $<1.5 \%$ up to $0.6 \mathrm{hPa}(\sim 52 \mathrm{~km})$, and differences between any one and the average of the three $<1 \%$. The consensus is equally good for the MWR-SBUV/2 afternoon-morning comparisons. However, it is poorer for the MWR, UARS-MLS, and SMILES morning-night comparisons, with $85 \%$ of the differences between pairs $<1.5 \%$ and the remaining up to $1.7 \%$.

We then compared hourly binned averages of the selected MWR data for the winters and summers from 1995 to 2013 with corresponding output from the NASA-Goddard GEOSCCM $_{\text {STRATTROP }}$ model for 2005. We found that the features seen in the measurements and model output mostly agree to better than the 1 to $1.5 \%$ statistical errors at the $2 \sigma$ level. There is one discrepancy worth noting. The MWR morning-night values are 2 to $3 \%$ higher than the modeled ones from 3.2 to $1.8 \mathrm{hPa}(\sim 39$ to $43 \mathrm{~km})$. Also, in winter, the measured values are increasing compared to the modeled values before sunrise in this region. The anomalies are statistically significant just before sunrise from 3.2 to $1.8 \mathrm{hPa}$. Direct intercomparisons between MWR, SMILES, and UARSMLS normalized morning-night profiles give no indication that the MWR values are overestimated during the pre-dawn and morning hours. Similar features appear in plots in literature describing results from other ground-based measurements. They provide support for the existence of a phenomenon driving increasing ozone values before dawn, but there are enough circumstantial differences between those observations and the present ones that they can not be taken to directly support the present result. Diurnal results derived from SMILES data are in good agreement with ours at 24, 34 , and $54 \mathrm{~km}$. At $44 \mathrm{~km}$ their data and model output are in good agreement while ours are not, and their measured diurnal values and ours are not consistent with respect to the morning maximum. This discrepancy weakens the case for increasing ozone values in the pre-dawn and morning hours in the upper stratosphere and remains to be resolved.
Acknowledgements. The SBUV/2, UARS-, and Aura-MLS data used in this effort were acquired as part of the activities of NASA's Science Mission Directorate, and are archived and distributed by the NASA-Goddard Earth Sciences Data and Information Services Center. The SBUV/2 effort is also supported by NOAA, as the instruments are aboard NOAA operational satellites. The SMILES instrument was jointly developed by the Japan Aerospace Exploration Agency (JAXA) and the National Institute of Information and Communications Technology. The L2 data were processed and distributed from the Institute of Space and Astronautical Science of JAXA under the supervision of M. Suzuki. We thank all those involved in developing these instruments, processing and understanding their data, and making them available to the research community. We likewise thank all those involved in the NASA-Goddard GEOSCCM modeling effort. We thank the International Space Sciences Institute for hosting a set of three workshops on characterizing ozone diurnal variations that several of us attended. This work was supported by NASA Grant NNX09AG85G. Field support for the MWR was provided by Jet Propulsion Laboratory and NOAA Mauna Loa Observatory staff. Work at the Jet Propulsion Laboratory, California Institute of Technology, was done under contract with NASA.

Edited by: M. Weber

\section{References}

Barath, F. T., Chavez, M. C., Cofield, R. E., Flower, D. A., Frerking, M. A., Gram, M. B., Harris, W. M., Holden, J. R., Jarnot, R. F., Kloezeman, W. G., Klose, G. J., Lau, G. K., Loo, M. S., Maddison, B. J., Mattauch, R. J., McKinney, R. P., Peckham, G. E., Pickett, H. M., Siebes, G., Soltis, F. S., Suttie, R. A., Tarsala, J. A., Waters, J. W., and Wilson, W. J.: The Upper Atmosphere Research Satellite microwave limb sounder instrument, J. Geophys. Res., 98, 10751-10762, 1993.

Chapman, S.: A theory of upper stratospheric ozone, Mem. R. Meteorol. Soc., 3, 103-125, 1930.

Connor, B. J., Siskind, D. E., Tsou, J. J., Parrish, A., and Remsburg, E. E.: Ground based microwave observations of ozone in the upper stratosphere and mesosphere, J. Geophys. Res., 99, 16757-16770, 1994..

Connor, B. J., Parrish, A., Tsou, J. J., and McCormick, M. P.: Error analysis for the ground-based microwave ozone measurements during STOIC, J. Geophys. Res., 100, 9283-9291, 1995.

DeLand, M. T., Taylor, S. L., Huang, L. K., and Fisher, B. L.: Calibration of the SBUV version 8.6 ozone data product, Atmos. Meas. Tech., 5, 2951-2967, doi:10.5194/amt-5-2951-2012, 2012.

Douglass, A. R. and Kawa, S. R.: Contrast between 1992 and 1997 high-latitude spring Halogen Occultation Experiment observations of lower stratospheric HCl, J. Geophys. Res., 104, 1873918754, doi:10.1029/1999JD900281, 1999.

Duncan, B. N., Strahan, S. E., Yoshida, Y., Steenrod, S. D., and Livesey, N.: Model study of the cross-tropopause transport of biomass burning pollution, Atmos. Chem. Phys., 7, 3713-3736, doi:10.5194/acp-7-3713-2007, 2007. 
Farman, J. C., Gardiner, B. G., and Shankin, J. D.: Large losses of total ozone in Antarctica reveal seasonal $\mathrm{ClO}_{\mathrm{X}} / \mathrm{NO}_{\mathrm{X}}$ interaction, Nature, 315, 207-210, 1985.

Frederick, J. E., Cebula, R. P., and Heath, D. F.: Instrument characterization for the detection of long term changes in stratospheric ozone: an analysis of the SBUV/2 radiometer, J. Atmos. Ocean. Tech., 3, 272-480, 1986.

Froidevaux, L., Read, W. G., Lungu, T. A., Cofield, R. E., Fishbein, E. F., Flower, D. A., Jarnot, R. F., Ridenoure, B. P., Shippony, Z., Waters, J. W., Margitan, J. J., McDermid, I. S., Stachnik, R. A., Peckham, G. E., Braathen, G., Deshler, T., Fishman, J., Hofmann, D. J., and Oltmans, S. J.: Validation of UARS Microwave Limb Sounder ozone measurements, J. Geophys. Res., 101, 10017-10060, doi:10.1029/95JD02325, 1996.

Froidevaux, L., Jiang, Y. B., Lambert, A., Livesey, N. J., Read, W. G., Waters, J. W., Browell, E. V., Hair, J. W., Avery, M. A., McGee, T. J., Twigg, L. W., Sumnicht, G. K., Jucks, K. W., Margitan, J. J., Sen, B., Stachnik, R. A., Toon, G. C., Bernath, P. F., Boone, C. D., Walker, K. A., Filipiak, M. J., Harwood, R. S., Fuller, R. A., Manney, G. L., Schwartz, M. J., Daffer, W. H., Drouin, B. J., Cofield, R. E., Cuddy, D. T., Jarnot, R. F., Knosp, B. W., Perun, V. S., Snyder, W. V., Stek, P. C., Thurstans, R. P., and Wagner, P. A.: Validation of Aura Microwave Limb Sounder stratospheric ozone measurements, J. Geophys. Res., 113, D15S20, doi:10.1029/2007JD008771, 2008.

Haefele, A., Hocke, K., Kämpfer, N., Keckhut, P., Marchand, M., Bekki, S., Morel, B., Egorova, T., and Rozanov, E., Diurnal changes in middle atmospheric $\mathrm{H}_{2} \mathrm{O}$ and $\mathrm{O}_{3}$ : observations in the Alpine region and climate models, J. Geophys. Res., 113, D17303, doi:10.1029/2008JD009892, 2008.

Huang, F. T., Reber, C. A., and Austin, J.: Ozone diurnal variations observed by UARS and their model simulation, J. Geophys. Res., 102, 12971-12985, doi:10.1029/97JD00461, 1997.

Huang, F. T., Mayr, H. G., Russell III, J. M., and Mlynczak, M. G.: Ozone diurnal variations in the stratosphere and lower mesosphere, based on measurements from SABER on TIMED, J. Geophys. Res., 115, D24308, doi:10.1029/2010JD014484, 2010

Imai, K., Manago, N., Mitsuda, C., Naito, Y., Nishimoto, E., Sakazaki, T., Fujiwara, M., Froidevaux, L., von Clarmann, T., Stiller, G. P., Murtagh, D. P., Rong, P.-P., Mlynczak, M. G., Walker, K. A., Kinnison, D. E., Akiyoshi, H., Nakamura, T., Miyasaka, T., Nishibori, T., Mizobuchi, S., Kikuchi, K.I., Ozeki, H., Takahashi, C., Hayashi, H., Sano, T., Suzuki, M., Takayanagi, M., and Shiotani, M.: Validation of ozone data from the superconducting Submillimeter-Wave LimbEmission Sounder (SMILES), J. Geophys. Res., 118, 57505769, doi:10.1002/jgrd.50434, 2013.

Kikuchi, K., Nishibori, T., Ochiai, S., Ozeki, H., Irimajiri, Y., Kasai, Y., Koike, M., Manabe, T., Mizukoshi, K., Murayama, Y., Nagahama, T., Sano, T., Sato, R., Seta, M., Takahashi, C., Takayanagi, M., Masuko, H., Inatani, J., Suzuki, M., and Shiotani, M.: Overview and early results of the superconducting Submillimeter-Wave Limb-Emission Sounder (SMILES), J. Geophys. Res., 115, D23306, doi:10.1029/2010JD014379, 2010.

Livesey, N. J., Read, W. G., Froidevaux, L., Waters, J. W., Santee, M. L., Pumphrey, H. C., Wu, D. L., Shippony, Z., and Jarnot, R. F.: The UARS Microwave Limb Sounder version 5 data set: theory, characterization, and validation, J. Geophys. Res., 108, 4378, doi:10.1029/2002JD002273, 2003.
Livesey, N. J., Read, W. G., Froidevaux, L., Lambert, A., Manney, G. L., Pumphrey, H. C., Santee, M. L., Schwartz, M. J., Wang, S., Cofield, R. E., Cuddy, D. T., Fuller, R. A., Jarnot, R. F., Jiang, J. H., Knosp, B. W., Stek, P. C., Wagner, P. A., and Wu, D. L.: Version 3.3 Level 2 data quality and description document, Version 3.3x-1.0, Jet Propulsion Laboratory, Pasadena, California, available at: http://mls.jpl.nasa.gov/data/v3-3_data_quality_ document.pdf (last access: December 2013), 2011.

Oman, L. D., Ziemke, J. R., Douglass, A. R., Waugh, D. W., Lang, C. Rodriguez, J. M., and Nielsen, J. E.: The response of tropical tropospheric ozone to ENSO, Geophys. Res. Lett., 38, L13706, doi:10.1029/2011GL047865, 2011.

Ogawa, H., Kawabata, K., Yonekura, Y., and Iwasaka, Y., Diurnal and Seasonal Variations of Strato-Mesospheric Ozone, J. Geomag. Geoelectr., 49, 1115-1126, 1996.

Pallister, R. C., Tuck, R. F., The diurnal variation of ozone in the upper stratosphere as a test of photochemical theory, Q. J. Royal Meteorologial Society, 109, 271-284, 1983.

Parrish, A.: Millimeter-wave remote sensing of ozone and trace constituents in the stratosphere, Proc. IEEE, 82, 1915-1929, 1994.

Parrish, A., deZafra, R. L., Solomon, P. M., and Barrett, J. W.: A ground-based technique for millimeter wave spectroscopic observations of stratospheric trace constituents, Radio Science, 23, 106-118, 1988.

Parrish, A., Connor, B. J., Tsou, J. J., McDermid, I. S., and Chu, W. P.: Ground-based microwave monitoring of stratospheric ozone, J. Geophys. Res., 97, 2541-2546, 1992.

Parrish, A., Boyd, I. S., Nedoluha, G. E. Bhartia, P. K., Frith, S. M., Kramarova, N. A., Connor, B. J., Bodeker, G. E., Froidevaux, L., Shiotani, M., and Sakazaki, T., Diurnal variations of stratospheric ozone measured by ground-based microwave remote sensing at the Mauna Loa NDACC site: measurement validation and GEOSCCM model comparison, Atmos. Chem. Phys. Discuss., 13, 31855-31890, doi:10.5194/acpd-13-31855-2013, 2013.

Rodgers, C. D.: Retrieval of atmospheric temperature and composition from remote measurements of thermal radiation, Rev. Geophys., 14, 609-624, 1976.

Rienecker, M., Suarez, M. J., Gelaro, R., Todling, R., Bacmeister, J., Liu, E., Bosilovich, M. G., Schubert, S. D., Takacs, L., Kim, G.K., Bloom, S., Chen, J., Collins, D., Conaty, A., da Silva, A., Gu, W., Joiner, J., Koster, R. D., Lucchesi, R., Molod, A., Owens, T., Pawson, S., Pegion, P., Redder, C. R., Reichle, R., Robertson, F. R., Ruddick, A. G., Sienkiewicz, M., and Woollen, J.: MERRA: NASA's Modern-Era Retrospective Analysis for Research and Applications, J. Climate, 24, 3624-3648, doi:10.1175/JCLI-D11-00015.1, 2011.

Rowland, F. J. and Molina, M. J.: Chloroflouromethanes in the environment, Rev. Geophys., 13, 1-35, 1975.

Sakazaki, T., Fujiwara, M., Mitsuda, C., Imai, K., Manago, N., Naito, Y., Nakamura, T., Akiyoshi, H., Kinnison, D., Sano, T., Suzuki, M., and Shiotani, M.: Diurnal ozone variations in the stratosphere revealed in observations from the Superconducting Submillimeter-Wave Limb-Emission Sounder (SMILES) on board the International Space Station (ISS), J. Geophys. Res. Atmos., 118, 2991-3006, doi:10.1002/jgrd.50220, 2013.

SPARC: Assessment of Trends in the Vertical Distribution of Ozone, edited by: Harris, N., Hudson, R., and Phillips, C., 
SPARC report No. 1, Global Ozone Research and Monitoring Project - Report No. 43, Geneva, 1998.

SPARC: Chemistry Climate Model Validation, edited by: Eyring, V., Shepherd, T. G., and Waugh, D. W., SPARC Report No. 5, Global Ozone Research and Monitoring Project Report No. 43, Geneva, 2010.

Strahan, S. E., Duncan, B. N., and Hoor, P.: Observationally derived transport diagnostics for the lowermost stratosphere and their application to the GMI chemistry and transport model, Atmos. Chem. Phys., 7, 2435-2445, doi:10.5194/acp-7-2435-2007, 2007.

Studer, S., Hocke, K., Schanz, A., Schmidt, H., and Kämpfer, N.: A climatology of the diurnal variations in stratospheric and mesospheric ozone over Bern, Switzerland, Atmos. Chem. Phys., 14, 5905-5919, doi:10.5194/acp-14-5905-2014, 2014.

UNEP: Handbook for the Montreal Protocol on substances that deplete the ozone layer, United Nations Environment Program, Ozone Secretariat, Nairobi, 2006.
Waters, J. W., Froidevaux, L., Harwood, R. S., Jarnot, R. F., Pickett, H. M., Read, W. G., Siegel, P. H., Cofield, R. E., Filipiak, M. J., Flower, D. A., Holden, J. R., Lau, G. K., Livesey, N. J., Manney, G. L., Pumphrey, H. C., Santee, M. L., Wu, D. L., Cuddy, D. T., Lay, R. R., Loo, M. S., Perun, V. S., Schwartz, M. J., Stek, P. C., Thurstans, R. P., Boyles, M. A., Chandra, K. M., Chavez, M. C., Gun-Shing, C., Chudasama, B. V., Dodge, R., Fuller, R. A., Girard, M. A., Jiang, J. H., Yibo, J., Knosp, B. W., LaBelle, R. C., Lam, J. C., Lee, K. A., Miller, D., Oswald, J. E., Patel, N. C., Pukala, D. M., Quintero, O., Scaff, D. M., Van Snyder, W., Tope, M. C., Wagner, P. A., and Walch, M. J.: The Earth Observing System Microwave Limb Sounder (EOS MLS) on the Aura satellite, IEEE T. Geosci. Remote., 44, 1075-1092, doi:10.1109/TGRS.2006.873771, 2006.

WMO (World Meteorological Organization): Scientific assessment of ozone depletion: 2010, Global Ozone Research and Monitoring Project - Report No. 52, Geneva, 2011. 